\title{
The Role of Peers in the Development of Social Anxiety in Adolescent Girls: A Systematic Review
}

\author{
Leanne Pickering $^{1,2} \cdot$ Julie A. Hadwin ${ }^{1} \cdot$ Hanna Kovshoff ${ }^{1}$ (I)
}

Received: 9 January 2019 / Accepted: 27 April 2019 / Published online: 16 May 2019

(c) The Author(s) 2019

\begin{abstract}
Pathways to social anxiety often reflect a set of complex and interacting factors that include both intrinsic and environmental factors. Theoretical models of social anxiety have highlighted that children and adolescents' peer experiences can increase risk for social anxiety. This systematic review explored the role of peers in the development of social anxiety in adolescent girls. It aimed to identify peer-related risk factors (i.e., peer acceptance, peer attachment, friendship quality, peer support, and victimisation) that place adolescents at risk for social anxiety, and to highlight those that are specific to girls. The findings showed that while low peer acceptance was significantly associated with increased social anxiety for boys and girls, limited close friendships, negative friendship experiences and relational victimisation were highlighted as risk factors specific to girls. The review suggested that researchers might usefully start to develop frameworks that capture generic, as well as gender-specific risk for social anxiety in adolescence. These will enable the development of prevention and intervention methods to support girls at increased risk and that focus on improving the quality of peer relationships.
\end{abstract}

Keywords Social anxiety $\cdot$ Gender $\cdot$ Girls $\cdot$ Peers $\cdot$ Mental health $\cdot$ Risk

\section{Introduction}

Anxiety is a feeling of worry or fear that occurs in response to the anticipation of future threat (American Psychiatric Association; APA 2013). Anxiety disorders are reported to be the most prevalent mental health need in the general population (Kessler et al. 2009), with worldwide prevalence rates estimated to be approximately $6.5 \%$ in children and adolescents (Polanczyk et al. 2015). In a survey of mental health of UK children and adolescents, Green et al. Goodman (2005) found that approximately $4 \%$ of adolescent boys and $5 \%$ of girls had a clinically recognised anxiety disorder.

Electronic supplementary material The online version of this article (https://doi.org/10.1007/s40894-019-00117-x) contains supplementary material, which is available to authorized users.

Hanna Kovshoff

H.Kovshoff@soton.ac.uk

1 Centre for Innovation in Mental Health - Developmental Lab, Department of Psychology, University of Southampton, Highfield, Southampton S017 1BJ, UK

2 Present Address: Children, Adults, Families, Health and Education, West Sussex County Council, Centenary House, Durrington Lane, Worthing, West Sussex BN13, UK
Researchers have found that individuals who experience a higher number of anxiety disorders during adolescence are at increased risk of later anxiety disorders and educational underachievement (Woodward and Fergusson 2001). Further studies have found that adolescent anxiety better predicts psychosocial outcomes in adulthood than childhood anxiety. For example, anxiety in adolescence was found to be strongly associated with adverse outcomes at age 30 , with adolescent anxiety significantly predicting poorer adjustment in adulthood, lower life satisfaction, poor coping skills and high chronic stress (Essau et al. 2014). Moreover, gender differences exist such that adolescent girls are at increased risk of developing anxiety disorders than boys (Essau et al. 2014). However, there is a paucity of research that specifically aims to understand gender-specific risk factors in the development of clinical levels of anxiety.

Although it is not uncommon for many people to experience social anxiety, particularly those with shy or inhibited temperaments, these feelings are often temporary or have minimal impact on daily life. When symptoms persist for an extended period of time and impair every day functioning, this profile can lead to a diagnosis of Social Anxiety Disorder (SAD; APA 2013). Symptoms of SAD include worries or fear associated with social situations where there is 
a chance of "scrutiny" or being "negatively evaluated" by others, and where situations are "avoided or endured with intense fear or anxiety" (APA 2013, p. 202). The diagnostic criteria highlight that children must experience social anxiety during interactions with peers, as well as adults, with this difficulty typically lasting for at least 6 months. It also states that the persistent and intense fear of social situations is disproportionate to the level of threat posed by the actual situation (APA 2013; National Institute for Health and Care Excellence 2013) and causes significant personal distress especially in social situations (e.g., meeting new people, speaking in public, eating in public, school attendance, working in groups and speaking in meetings).

While researchers have reported that SAD has an estimated 12 -month prevalence rate of approximately $7 \%$ in community populations of adults (Fehm et al. 2005; Kessler et al. 2005), lifetime prevalence rates may be as high as $10.7 \%$ (Kessler et al. 2012). The onset of social anxiety typically emerges during early to mid-adolescence, at a median age of approximately 13 years (APA 2013; Merikangas et al. 2010). Research has indicated that $75 \%$ of individuals experience first onset by the age of 15 years (Kessler et al. 2005), with rates of SAD increasing sharply after the age of nine and that peak in adolescents between 10 and 19 years (Beesdo et al. 2007). Research has also found cross-cultural differences in prevalence rates; approximately $4 \%$ of Turkish adolescents were found to experience SAD (Demir et al. 2013) compared with 3\% of Finnish adolescents (Ranta et al. 2009). Furthermore, gender differences indicate that women consistently show higher rates of social anxiety than men, both in the past 12 months (6.5\% versus 4.8\%; McLean et al. 2011 ) and across the lifetime (12.3\% versus $8.9 \%$; Kessler et al. 2012).

Several studies have found that individuals diagnosed with SAD or who experience elevated symptoms of social anxiety are at risk of poorer outcomes relative to their nonsocially anxious peers. For example, in a retrospective study of the impact of anxiety disorders on educational outcomes, researchers found that nearly half $(48.8 \%)$ of individuals with anxiety disorders reported having left school prematurely and that $61.2 \%$ of these individuals had a diagnosis of SAD (Van Ameringen et al. 2003). Leaving school prior to the completion of high school may have a long-term impact on an individual's well-being and life satisfaction (Stein and Kean 2000). Even in the absence of depression, at least half of adults with social anxiety have been found to report a substantially reduced quality of life, including poorer general health, mental health and social functioning; this in turn negatively impacted on their work performance, employment and social relationships (Wittchen et al. 2000).

Further research has shown that young people with SAD are at increased risk of developing secondary mental health difficulties. SAD has been found to be positively associated with subsequent depression (the risk being threefold for individuals with SAD relative to those with no anxiety disorders; Beesdo et al. 2007) and increased suicide attempts (Bolton et al. 2008; Davidson et al. 1993; Khan et al. 2002). The impact of SAD across development may therefore be partially accounted for through comorbidity with depressive disorders, where both are linked to poorer outcomes, including longer duration of illness and increased risk of attempted suicide (Stein et al. 2001). A further body of research has linked SAD to an increased risk of alcohol dependence and substance abuse (Buckner et al. 2008a, b). Adolescents with SAD have been found to be twice as likely to have severe alcohol use disorder than their non-anxious peers, with socially anxious females more likely to develop alcohol problems in late adolescence and early adulthood compared with early to mid-adolescence in males (Black et al. 2015). However, it has also been suggested that, as well as being a risk factor for cannabis use, SAD may serve as a protective factor due to its association with reduced levels of peer involvement (Nelemans et al. 2016).

Several theoretical frameworks have been developed to understand the causal pathways leading to SAD, which highlight a complex set of factors linked to its onset (Tillfors 2004). These include intrinsic or within-individual factors (e.g. genetics, temperament and cognitive biases) (Ollendick and Hirshfeld-Becker 2002) and extrinsic or environmental factors (e.g. parenting and social relationships) (Brook and Schmidt 2008). Based on a review of recent literature, Spence and Rapee (2016) proposed a framework of social anxiety, which described an interaction between intrinsic and environmental factors that increases the risk of developing SAD. They suggested that children who are intrinsically predisposed to social anxiety, either through genetics or temperament, are at risk of SAD if exposed to environmental risk factors. These factors then impact on the young person's social skills, problem solving behaviour and coping strategies. With social anxiety perceived as being on a continuum, risk factors may lead to heightened anxiety levels which meet the criteria for a diagnosis of SAD. While some risk factors are likely to be involved in the development of social anxiety, Spence and Rapee (2016) argued that a lack of prospective research means that there is insufficient evidence to establish causation and that some factors may only be involved in a maintenance cycle.

One longitudinal study captured the complexity of developmental pathways leading to SAD. It tracked the development of mental and physical health from preadolescence into adulthood (the TRacking Adolescents' Individual Lives Survey 'TRAILS' study; van Oort et al. 2011); participants aged 10-12 years were followed up biannually to identify potential risk factors for anxiety and depression. The results of growth modelling identified a number of generic risk factors for different anxiety types, with risk factors for SAD 
including temperament, self-esteem, peer factors, parenting and parental mental health. Furthermore, being a victim of bullying was a stable and long-term risk factor for social anxiety, alongside low sociometric status and being a bully.

Behavioural inhibition (BI) is a temperament characterised by heightened vigilance to threat and novelty, social reticence, and withdrawal from engaging with unfamiliar peers (Fox 2010). Children who show BI have been found to be at greater risk of developing SAD in adolescence, with this relationship being stronger in girls (Schwartz et al. 1999). In support a meta-analysis that included seven longitudinal studies showed a sevenfold increase in risk of developing SAD for BI children (Clauss and Blackford 2012).

In support of genetic risk factors, Stein et al. (1998) found a tenfold risk for SAD in first-degree relatives of socially anxious individuals relative to non-anxious individuals. After recruiting 23 adults diagnosed with SAD, all firstdegree relatives aged 16 and over took part in diagnostic interviews based on DSM-IV criteria. While $26.4 \%$ of relatives of the SAD group experienced general social anxiety, this compared with only $2.7 \%$ of relatives for the comparison group. Consistently, research has found that mothers' social anxiety significantly predicts anxiety in offspring (Bögels et al. 2001) and that there is an association between SAD in offspring and parental social anxiety, another anxiety disorder and depression (Lieb et al. 2000). A recent meta-analysis was conducted to explore genetic and environmental contributions to SAD in both children and adults. Using data from 12 twin studies, involving a total sample of 42,585 children and adults from Europe, the USA and Australia, an estimated heritability of $54 \%$ for SAD in children relative to $27 \%$ in adults was found, with most of the remaining variance being accounted for by non-shared environmental factors in both groups (Scaini et al. 2014).

Further studies have explored the role of environmental factors (e.g., parenting, illness and peer relationships) in the onset of SAD. For example, parental control, overprotection and parental mental health have been linked to its development (Brook and Schmidt 2008). The impact of parenting on the emergence of anxious affect has been associated with several risks; parents who themselves experience anxiety are argued to model their own fears of social situations and are less likely to facilitate social experiences for themselves or their children (Ollendick and Hirshfeld-Becker 2002). In addition, parent rejection was found to be a significant predictor of child social anxiety (Festa and Ginsburg 2011) and it has been shown that socially anxious children judge their parents as less emotionally warm and more rejecting than non-socially anxious children (Bögels et al. 2001). Furthermore, research has indicated that maternal overprotection is a significant predictor of children's social anxiety (Bögels et al. 2001; review by Möller et al. 2016) and that fathers of children with high social anxiety are more controlling than those with less anxious children (Greco and Morris 2002).

Although the relationship between children and their parents is particularly important in childhood and preadolescence, peer relationships take on greater importance in adolescence as young people spend increasing amounts of time with their peer group (Furman and Buhrmester 1992; Prinstein et al. 2001) and become particularly vulnerable to social embarrassment (Ollendick and Hirshfeld-Becker 2002). In a review of cumulative risk factors for social anxiety and depression, Epkins and Heckler (2011) reported that peer-related risk factors were more strongly linked to child and adolescent social anxiety than family-related variables. They also highlighted possible gender differences across a number of different peer-related risk factors including peer acceptance and rejection, victimization, and loneliness, with mixed results. The finding that negative peer relations may serve as an important risk factor for the development of SAD later in life, could partly be accounted for through developmental cascade effects, where problems in one area could undermine functions in other domains and form part of a negative pathway to social anxiety (Masten 2014; Masten and Cicchetti 2010).

A large body of work has aimed to demonstrate that elevated social anxiety is associated with difficult peer relationships (Bracik et al. 2012). Studies have found that children with SAD experience lower quality friendships than their non-anxious peers (Baker and Hudson 2015), are more likely to perceive themselves as less socially accepted (Ginsburg et al. 1998) and to respond more poorly to negative peer feedback (Kujawa et al. 2014). Although socially anxious adolescents have also been found to have social relationships characterised by submissive behaviour (Walters and Inderbitzen 1998), further evidence indicates that the quality of friendships can increase risk for, or provide protection from, the development of social anxiety. For example, Festa and Ginsburg (2011) found that children who experienced validation and acceptance in their friendships were less likely to experience symptoms of social anxiety. While research has also suggested that increased peer support is associated with decreased social anxiety (Cavanaugh and Buehler 2016), evidence remains inconsistent, with Grills-Taquechel et al. (2010) finding that poor adolescent peer support did not predict social anxiety.

\section{The Current Study}

The current evidence base suggests that adolescent girls are at increased risk of developing social anxiety disorder relative to boys (DeWit et al. 2005); however, understanding the risk profile for adolescent girls (vs. boys) has not been a direct focus of current research. Moreover, 
evidence indicates that there are consistent gender differences in child and adolescent peer experiences (Rose and Rudolph 2006), but those aspects of peer relations that are critically important in the development of social anxiety in girls are unclear. To increase our understanding of peerrelated risk and protective factors, this systematic review examined the role of peers in the development of social anxiety in adolescent girls, Specifically, it considered what role peer relationships have in identifying gender specific pathways for the development of social anxiety in girls. Its aims were threefold: (1) to collate and appraise the available evidence to guide further research study, (2) to inform interventions to promote the development of positive peer experiences; and (3) to highlight target areas of support for adolescent girls at risk of social anxiety.

\section{Method}

\section{Search Strategy}

A systematic search of the literature was conducted using two electronic databases: PsycINFO via EBSCO and Web of Science (1970-2016). The search terms used in this literature review included "social anxiety" or "social anxiety disorder" or "social phobia" and peer or "peer relation*" or interpersonal or classmate or "social relation*" or friend* or "peer group*". The list of search terms was generated by the first author based on key terms identified in research papers during the initial searches. The thesaurus function was also used to explore related terms and constructs.

In PsycINFO, the results were filtered by limiters including publication (peer reviewed only), language (English), population (female) and age groups (school age 6-12 years; adolescence 13-17 years). In Web of Science, articles were filtered by publication type (article only) and language (English) and later refined by Topic (adolescen* or child*).

\section{Inclusion and Exclusion Criteria}

The search was completed in October 2016 and resulted in the identification of 839 articles to be screened by title and abstract. At this stage, studies were excluded if they met the exclusion criteria or did not relate to the research questions being addressed. A total of 63 articles were retrieved in full and assessed for eligibility against the inclusion and exclusion criteria. A total of 24 articles met the criteria for extraction and were included in this review; no qualitative research was found. Articles were only included if they involved pre-adolescent or adolescent girls aged between 10 and 17 years. Studies were excluded from the review if they did not involve participants within this age range. Research articles were only included if they measured social anxiety as an outcome variable and included data pertaining to the development of social anxiety. It was also necessary for research articles to include separate data for girls relating to the role of peers in the development of social anxiety. Reasons for exclusion of $(n=39)$ papers are highlighted in supplementary analysis in Online Resource 4.

A summary of the systematic search strategy utilised in this review is shown in Fig. 1. Information was extracted from the articles about authors, country, design, participants, measures of social anxiety, peer relationship measures, and relevant research findings. Following extraction and drafting of the report, the search was re-run in July 2017 to check whether any new papers were published in the interim since the initial and did not result in any additional articles.

\section{Quality Assessment}

All studies were quantitative and involved either a cross-sectional $(n=12)$ or longitudinal $(n=12)$ design. The longitudinal studies were conducted over two or three time points and included timespans of 3 years $(n=1), 2$ years $(n=3), 1$ year $(\mathrm{n}=4), 9$ months $(\mathrm{n}=3)$ and 2 months $(\mathrm{n}=1)$. The studies were assessed for quality using a modified tool based on the Downs and Black (1998) checklist and the Quality Assessment Tool for Observational Cohort and Cross-Sectional Studies (National Institute of Health 2014). Consideration was given to a number of key areas including the reliability and validity of the measures used, potential confounding variables, participation rate and representativeness of the population, and the duration of the research. The 18 criteria for assessment are shown in Online Resource 1. Fourteen criteria apply to all studies and an additional 4 to those with a longitudinal design; therefore total quality is given as a proportional score.

The results of the quality assessment shown in Online Resource 2 for each study shows that the scores for crosssectional studies $(\mathrm{n}=12)$ ranged from 0.52 to 0.79 , while longitudinal studies $(n=12)$ ranged from 0.67 to 0.89 . This range of scores indicates that most studies were of an acceptable standard, with those use longitudinal designs being marginally higher. The majority of studies reported their aims or hypotheses (23/24), as well as the characteristics of participants (24/24), only a third provided detailed information on their inclusion and exclusion criteria. The majority (20/24) had a representative community-based sample of participants, with 14 studies reporting a participation rate of $>50 \%$. All studies provided a good description of the measures used, with the majority (23) providing a detailed and clear description of their main findings.

Of the longitudinal studies, the majority had a sufficient timeframe to detect a change in social anxiety, with only one study having a particularly short time of 2 months (Siegel et al. 2009). Loss to follow-up was widely considered by 
Fig. 1 Flow chart detailing the results of the systematic search process and the application of the inclusion and exclusion criteria

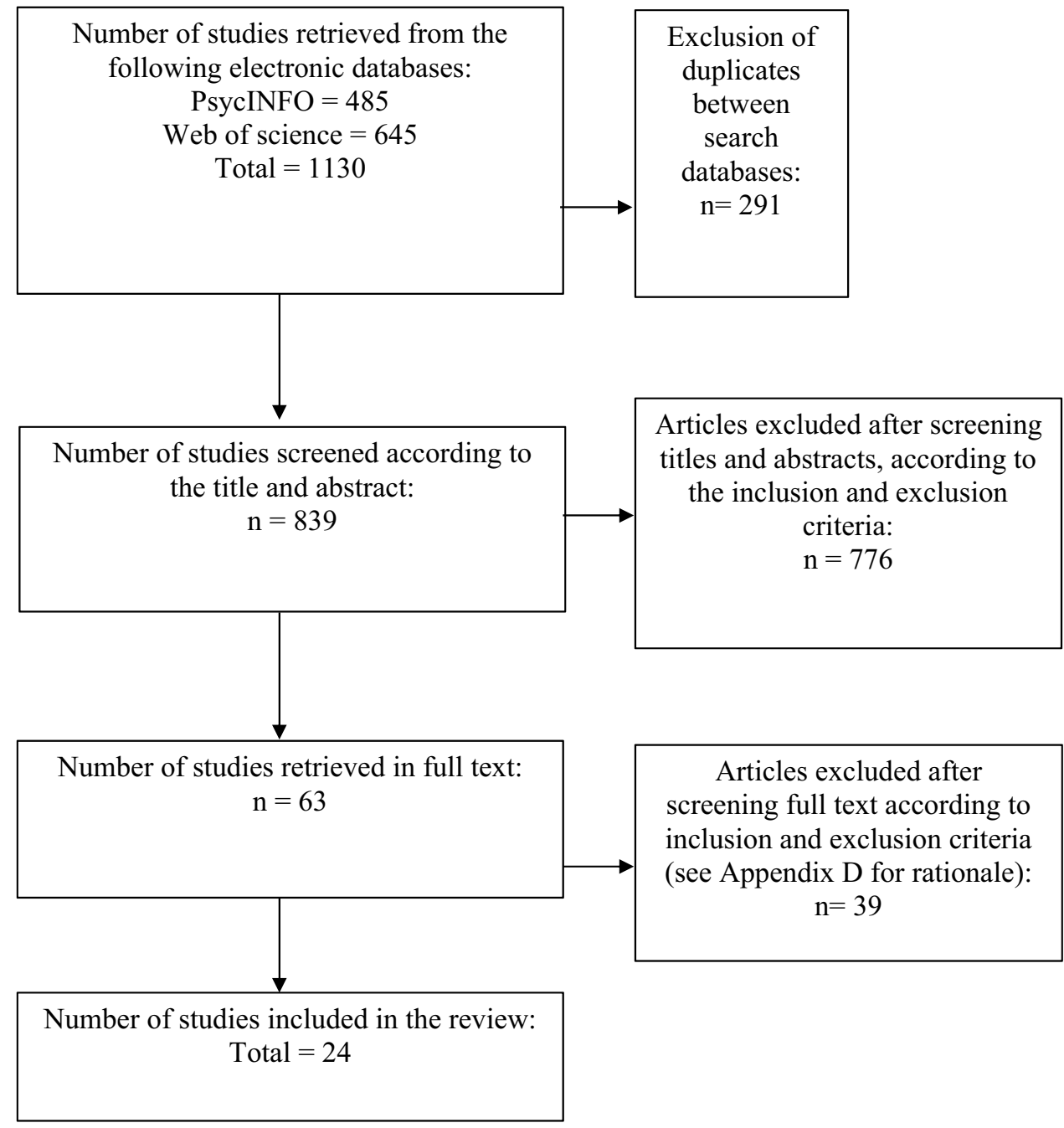

the studies in this review, with 7 (/12) experiencing a loss of $>20 \%$.

\section{Results}

\section{Participants}

A summary of the method and result for each of the 24 studies is shown in Table 1. This table shows that participants in the 24 studies ranged from age 8 to 19 years, with all studies including a number of participants aged between 12 and 15 years, the majority of studies $(n=17)$ included participants within the 13-14-age range. The total number of participants involved in each study varied from 66 to 5537. While $50 \%$ of the studies included between 205 and 561 participants, $25 \%$ had fewer than 200 and $25 \%$ over 1500 . Twenty-one studies included a mixed group of participants, with the remaining three included females only. The gender ratio in the mixed studies was approximately equal, with three including $>60 \%$ girls.

The majority of studies were conducted in the USA $(n=17)$, with one study each from Finland, the Netherlands, Sweden, Western Europe, Canada, China and Taiwan. The ethnicity of participants was consistently reported across studies from the USA. Of these, the majority had a predominantly Caucasian population $(n=12)$, with 10 studies consisting of $>70 \%$ Caucasian participants. Three studies included $>67 \%$ Hispanic participants and two $>50 \%$ African American.

\section{Measures of Social Anxiety}

The outcome measures of social anxiety were largely consistent across studies, with a total of 14 administering directly comparable measures including the Social Anxiety Scale for Adolescents (La Greca and Lopez 1998) and the Social Anxiety Scale for Children-Revised (La Greca 1999; La Greca and Stone 1993). A further five studies 


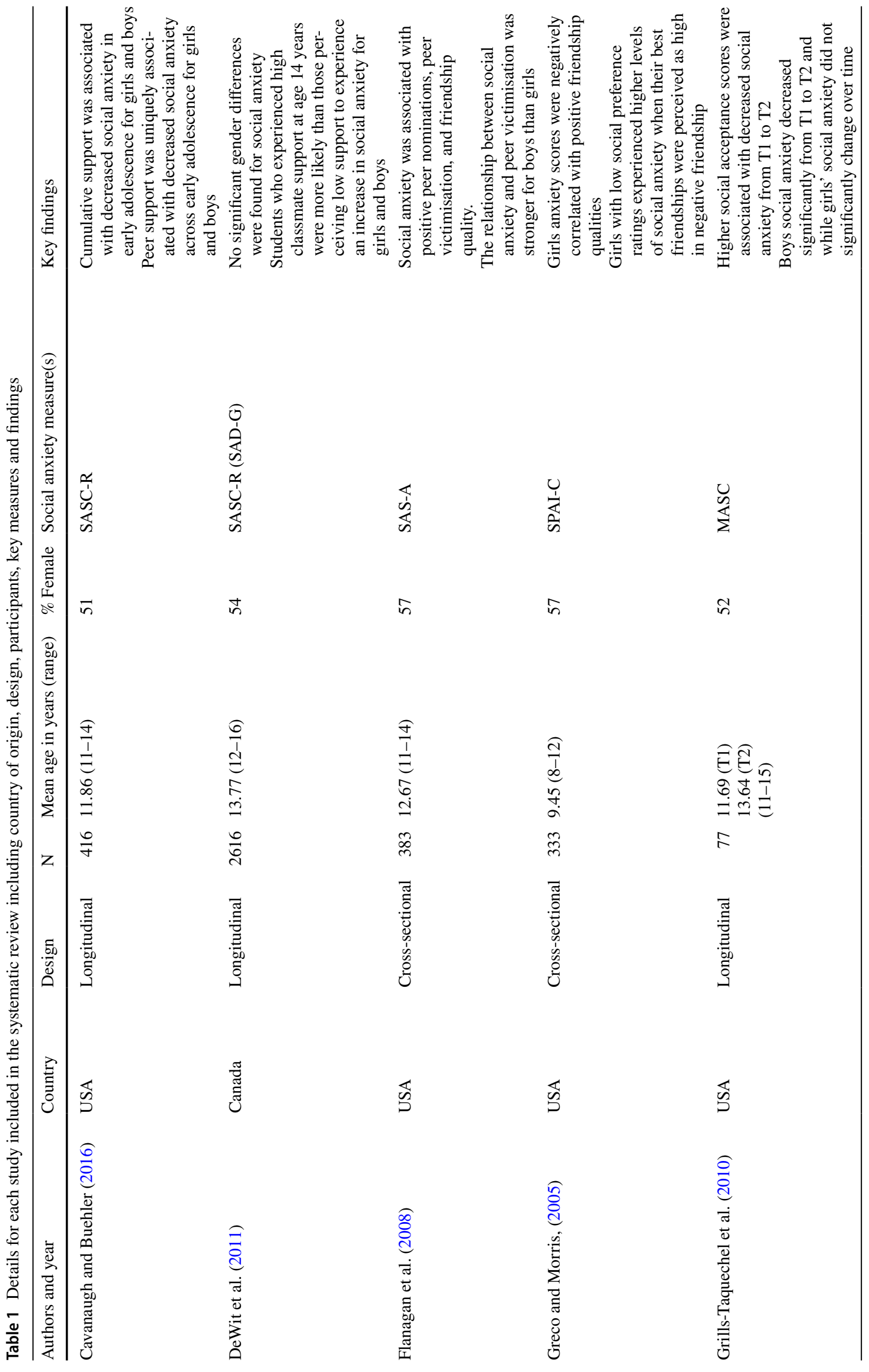




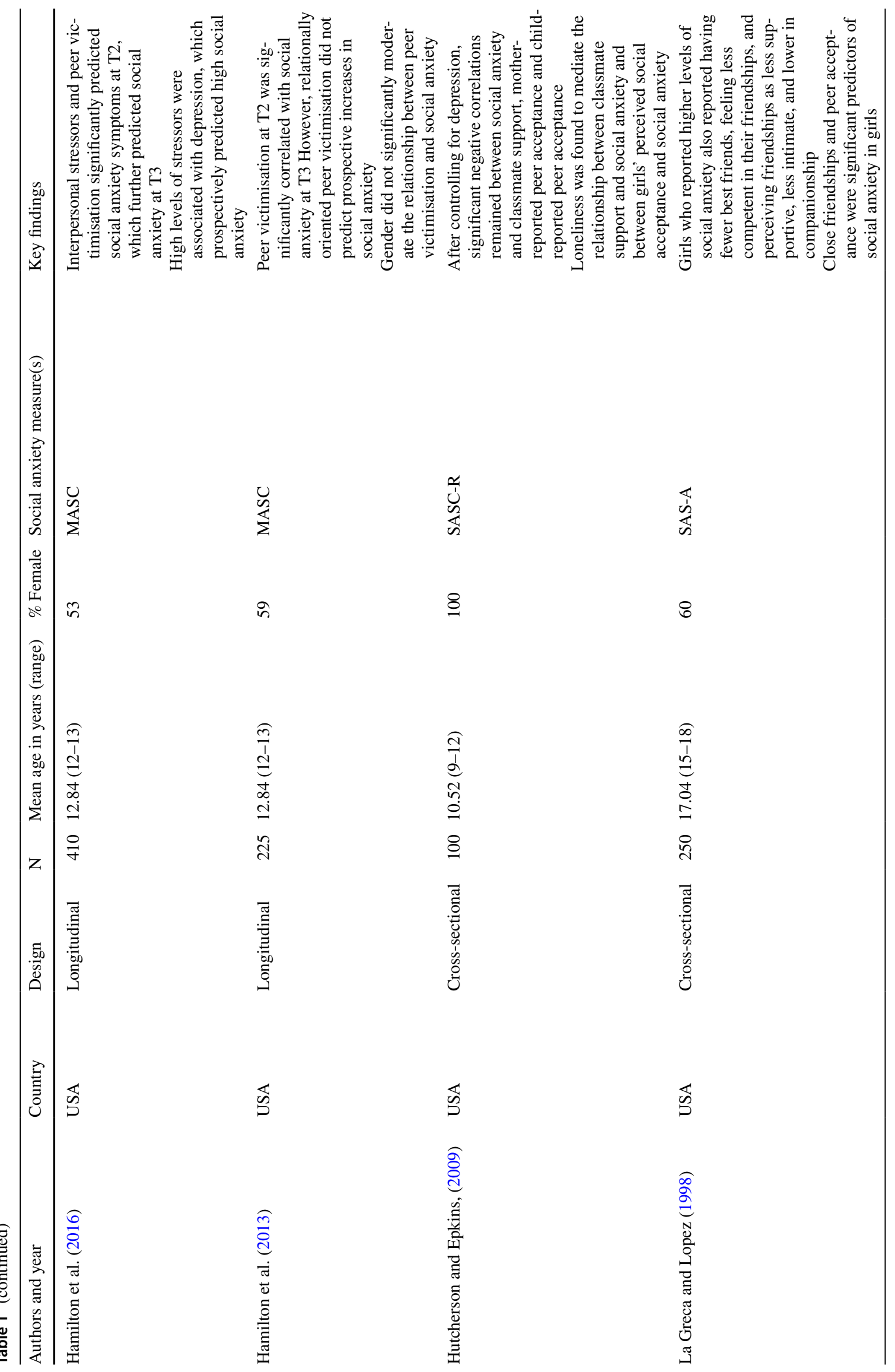




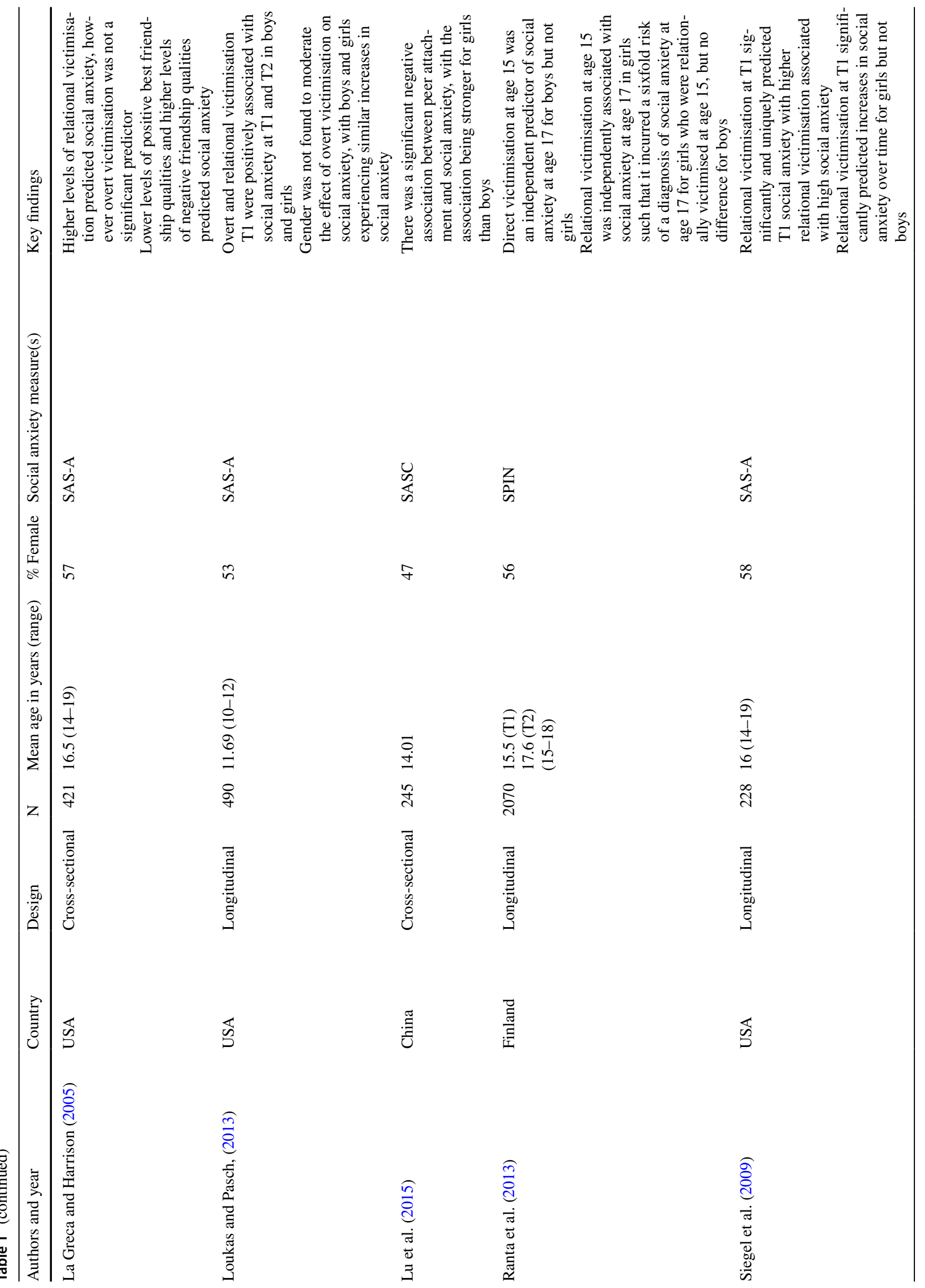




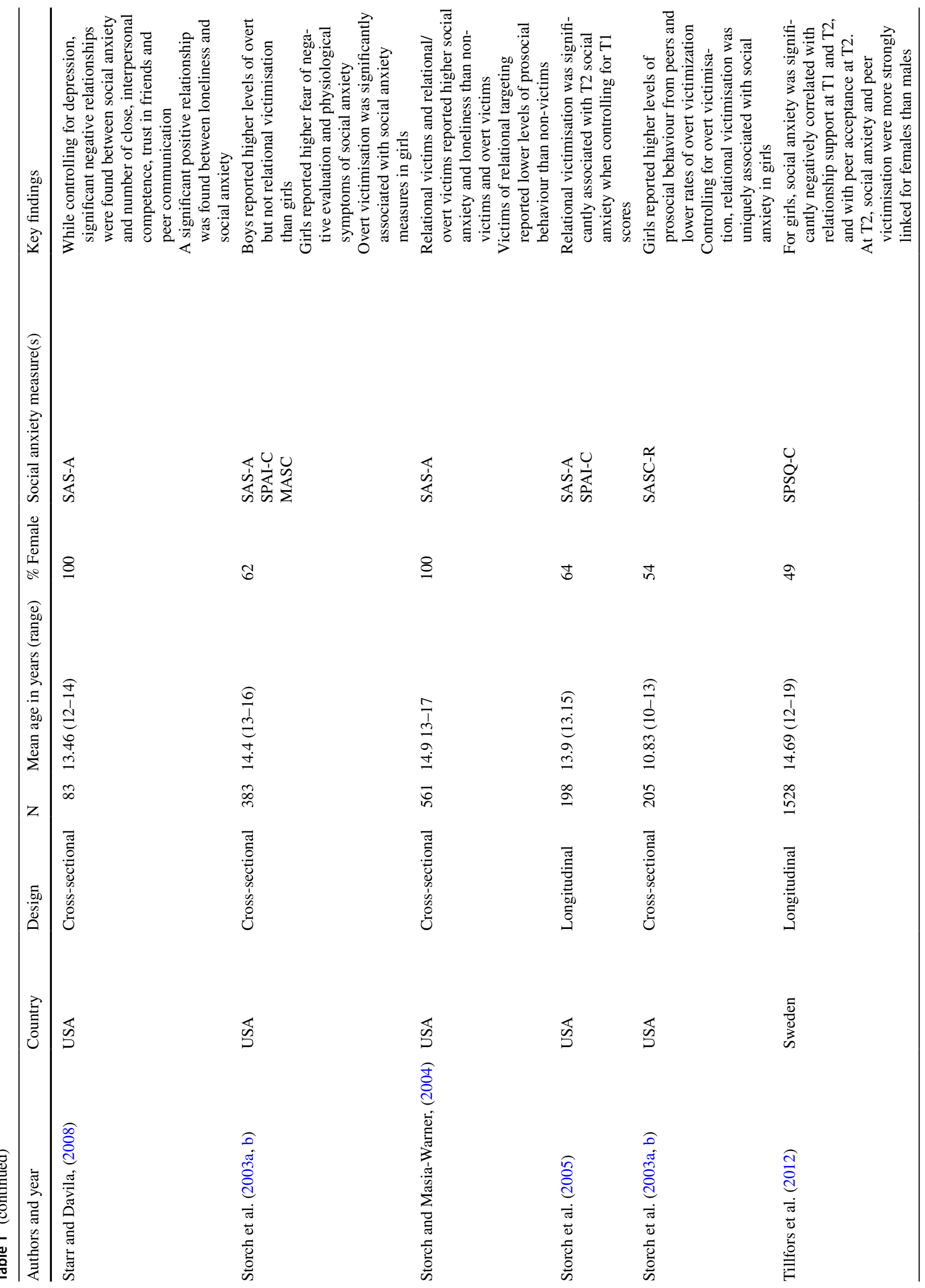




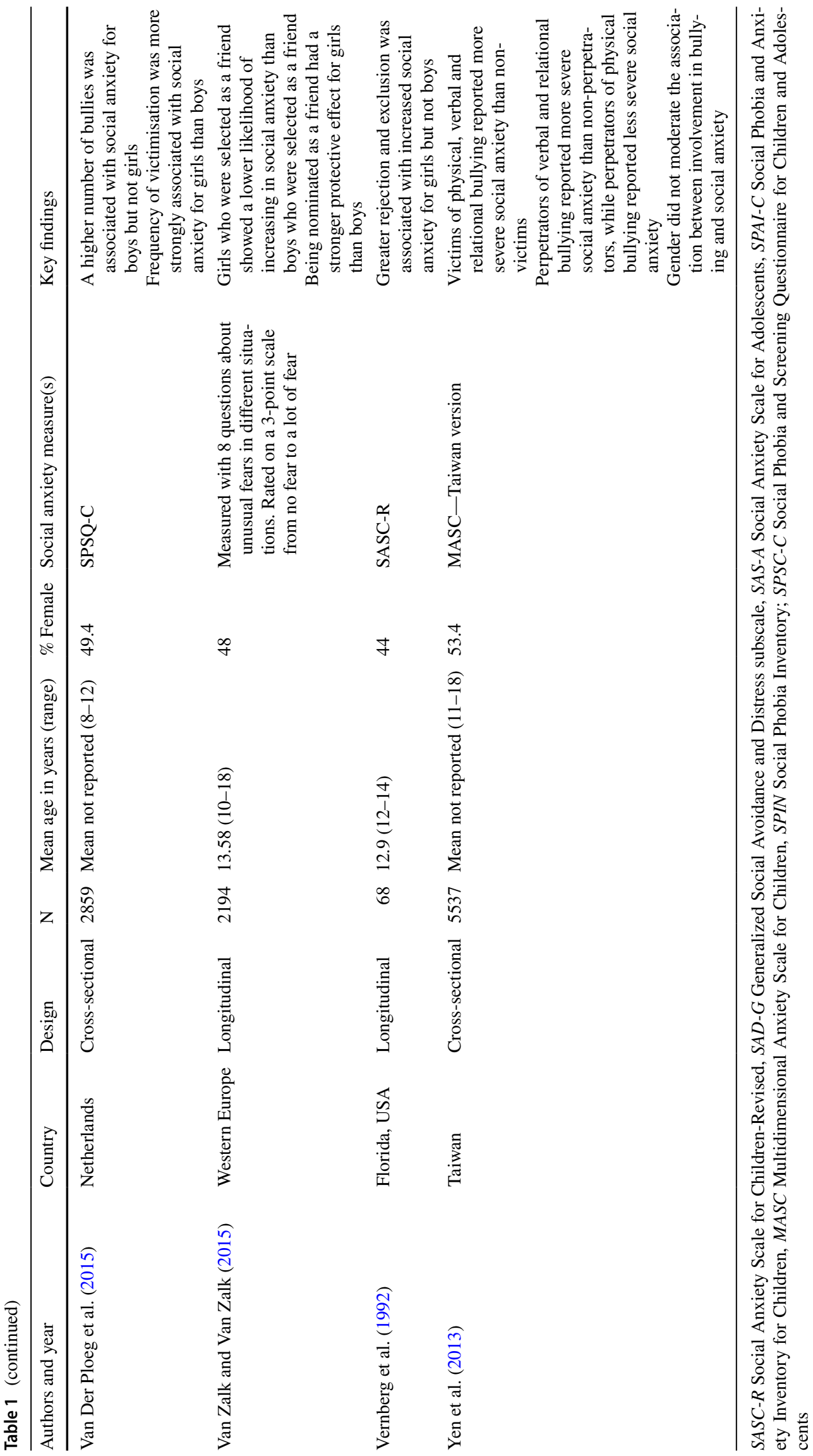


administered the Multidimensional Anxiety Scale for Children (March 1997), with the remainder using the Social Anxiety Scale for Children (La Greca et al. 1988), the Social Phobia and Anxiety Inventory for Children (Beidel et al. 1995, 1998), the Social Phobia Inventory (Connor et al. 2000) and the Social Phobia Screening Questionnaire for Children (Gren-Landell et al. 2009).

The Social Anxiety Scales for Children (Revised) and Adolescents consist of three subscales including: fear of negative evaluation from peers, general social avoidance and distress, and social avoidance and distress of new social situations and unfamiliar peers (La Greca and Lopez 1998). Reliability for these measures was reported across studies, with internal consistency found to be adequate or above.

\section{Measures of Peer Relationships}

As different aspects of peer relationships were explored by the studies in this review, a range of measures was used to gather data on (1) peer acceptance, (2) peer support, (3) friendship quality and (4) peer victimization. While some measures were administered across multiple studies, others were less frequently used.

Three of the four studies which measured (1) peer acceptance in this review used the six-item self-report social acceptance subscale of the Self-Perception Profile for Children (Harter 1985) or Adolescents (Harter 1988), with internal consistency reported to be acceptable on both measures (Grills-Taquechel et al. 2010; Harter 1988; Hutcherson and Epkins 2009; La Greca and Lopez 1998). One study used factor analysis to identify items from multiple measures that loaded onto a latent Peer Acceptance variable (La Greca and Lopez 1998), while others developed their own measures based on the number of peer nominations young people received (Flanagan et al. 2008; Tillfors et al. 2012). Although the latter is not directly comparable with the selfreport Self-Perception Profile for Children or Adolescents, it does provide an indication of acceptance through peer reported nominations.

Measures of (2) peer support were more varied. Three studies used the classmate and close friend subscales of the Social Support Scale for Children (Harter 1985), other measures included a five-item Friend Support Scale (Richman and Bowen 1997), the seven-item Children's Friendship Scale (Berndt and Perry 1986; Vernberg et al. 1992), the Social Support Appraisal Scale from the Survey of Children's Social Support (Dubow and Ullman 1989) and the relationship support subscale of the Friendship Qualities Questionnaire (Parker and Asher 1993). Internal consistency was reported to be adequate for all measures. Although Tillfors et al. (2012) administered 14 items from the Friendship Qualities Questionnaire and used factor analysis to identify two latent variables of relationship support and negativity; relationship support consisted of 10 items and had good internal consistency at two time-points.

Table 3 shows that (3) Friendship quality was measured using a variety of self-reported questionnaires including the aforementioned Friendship Qualities Questionnaire $(n=3)$, the Friendship Interview $(n=1)$, the Adolescent Interview (adapted from the Friendship Interview; Vernberg 1990; $\mathrm{n}=1$ ), the Network of Relationship Inventory-Revised $(\mathrm{n}=1$; Furman and Buhrmester 1985), the Self-Perception Profile for Adolescents $(n=2)$ and the Social Support Scale for Children $(n=1)$. Most studies administered only one measure, La Greca and Lopez (1998), and others identified subscales from multiple measures that loaded onto a latent friendship factor. Of the three studies that used the Friendship Qualities Questionnaire, only one administered the full 40-item scale (Greco and Morris 2005) and internal consistency was reported to be adequate or good for all three studies.

A range of (4) peer victimization measures was also used across studies including the Social Experiences Questionnaire (Crick and Grotpeter 1996; $n=7$ ), the Revised Peer Experiences Questionnaire $(\mathrm{n}=2)$, the Victimization Questionnaire $(\mathrm{n}=1)$, the Olweus Bully/Victim Questionnaire (Olweus 1996), the Rejection Experiences Questionnaire and the School Bullying Experience Questionnaire $(\mathrm{n}=1)$. Although the Social Experiences Questionnaire was the most frequently used self-report measure, and has been shown to have good reliability and validity (Crick and Grotpeter 1996), most studies administered different variants of the scale. While two studies administered only the relational victimization subscale to assess social exclusion and reputational threat (Hamilton et al. 2013, 2016), others administered modified versions such as by adding questions to the subscales of overt and relational victimization (Storch et al. 2003a; Storch and Masia-Warner 2004). However, internal consistency was reported to be good for the relational subscale by all but one study, and adequate for overt victimization.

\section{Gender Differences in Social Anxiety}

A number of studies reported that there was no significant gender difference in levels of social anxiety (DeWit et al. 2011; Flanagan et al. 2008; Grills-Taquechel et al. 2010; La Greca and Harrison 2005; Siegel et al. 2009), eight studies found that girls scored significantly higher on measures of social anxiety than boys (e.g. Hamilton et al. 2016; Storch et al. 2003a; Yen et al. 2013); age ranges were comparable across significant and non-significant studies. For example, in an early piece of research exploring social anxiety in adolescents aged $15-18$ years $(n=250)$, La Greca and Lopez (1998) found that girls reported more total social anxiety than boys. This contrasts with a more recent study by La 
Greca and Harrison (2005) who found no significant gender difference. More specifically, differences have been found on individual subscales of social anxiety, with girls reporting significantly higher levels of fear of negative evaluation (La Greca and Lopez 1998; Storch et al. 2003a) and general avoidance and distress than boys (Storch et al. 2003b), as well as more physiological symptoms (Storch et al. 2003a).

The results from longitudinal studies have shown that girls self-reported significantly more social anxiety over time than boys. In studies of adolescents aged 12-13 years, Hamilton et al. (2016) found that girls reported higher levels of social anxiety than boys at baseline and nine month follow-up ( $n=410)$, while Hamilton et al. (2013) found that this difference remained at 18 months $(n=225)$. Similarly, in their study of early adolescents aged $10-14$ years $(n=490)$, Loukas and Pasch (2013) found that after controlling for social anxiety levels at baseline, girls reported significantly higher levels than boys one year later. This indicates that higher baseline levels do not account for the increased social anxiety experienced by girls over time. Although GrillsTaquechel et al. (2010) found that there was no significant gender difference in social anxiety scores at baseline or at two year follow up $(n=77)$, the pattern of results differed between boys and girls. While girls social anxiety increased slightly over time, boys reported a significant decrease between age 11 and 15 years. This indicates that gender may have a moderating role in the development of social anxiety across childhood and adolescence.

\section{Risk Factors and the Development of Social Anxiety}

\section{Peer Acceptance}

Six studies in this review explored the relationship between peer acceptance and social anxiety, with peer acceptance defined by Greco and Morris (2005, p. 197) as "the extent to which a child is liked or noticed by their peer group". This construct differs from friendship in that it does not require a mutually reciprocal relationship. In their cross-sectional study on peer relationships in adolescence, La Greca and Lopez (1998) used the Self-Perception Profile for Adolescents (Harter 1988) to explore the association between peer acceptance and social anxiety. They found that low peer acceptance was significantly associated with social anxiety in boys and accounted for between $10 \%$ and $17 \%$ of variance in social anxiety scores. For girls, both close friendships and peer acceptance significantly and negatively predicted social anxiety, together accounting for between $29 \%$ and $43 \%$ of variance. Low peer acceptance continued to significantly predict higher social anxiety in girls, after controlling for the contribution of friendship quality (La Greca and Lopez 1998). The results suggest that peer acceptance may be a significant factor in the development of social anxiety in adolescent girls. This is further supported by Hutcherson and Epkins (2009) who found that social anxiety in preadolescent girls $(n=100,9-12$ years) was significantly and negatively associated with both mother and child reported peer acceptance.

Longitudinal research has also found a significant association between peer acceptance and social anxiety. For example, Grills-Taquechel et al. (2010) found that selfperceived social acceptance significantly and uniquely predicted adolescents' social anxiety two years later with higher social acceptance from their peers associated with decreased social anxiety at age 13-14 years. However, as no interaction effect was found between social acceptance and gender, this indicates that the association between peer acceptance and social anxiety was consistent for boys and girls. Perceived social acceptance could therefore be considered as an important protective factor against social anxiety, with Grills-Taquechel et al. (2010) suggesting that this may highlight the importance of a sense of belonging, of which peer acceptance is an important part.

In a further cross-sectional study exploring the relationship between peer acceptance and social anxiety, Flanagan et al. (2008) used the peer social network diagram (Lansford and Parker 1999; Parker and Herrera 1996) to obtain adolescents' positive peer nominations $(n=383$, 11-14 years). Although similar to sociometric measures, this method only includes unilateral nominations of friendships, with group-level peer acceptance based on the number of nominations adolescents received. Flanagan et al. (2008) found a significant negative correlation between peer nominations and social anxiety, indicating that increased peer acceptance was associated with low social anxiety. Using a similar peer nomination approach, Tillfors et al. (2012) examined the prospective links between adolescent peer relations and social anxiety in Swedish students $(n=1528)$ aged 12-19 years. After controlling for age, a significant and negative concurrent correlation was found between peer acceptance and social anxiety, but only for girls at one-year follow-up. Although peer acceptance uniquely predicted decreases in social anxiety over time for both genders, this relationship was not bi-directional. This further indicates that heightened levels of social anxiety do not account for low peer acceptance, but that being accepted by peers may serve as a protective factor against the development of social anxiety during adolescence.

\section{Peer Attachment}

Two studies in this review explored the association between peer attachment and social anxiety using the Inventory of Parent and Peer Attachment (Armsden and Greenberg 1987), with peer attachment defined as an affective bond between adolescents and their peers (Lu et al. 2015). In a study 
involving both deaf $(n=112)$ and hearing $(n=133)$ adolescents aged 10-15 years, Lu et al. (2015) found that for children with normal hearing, peer attachment was significantly and negatively correlated with social anxiety. Further analysis of the results by gender found that for hearing children, this association was stronger for girls than boys. The quality of adolescent girls' relationships with their peers $(n=83$, 13-14 years) was assessed in more depth in a study by Starr and Davila (2008), who found that social anxiety was significantly and negatively associated with the peer attachment variables of trust in friends and peer communication, after controlling for depression; the association between greater alienation with friends and social anxiety was marginally non-significant. Although this suggests that peer attachment may be specifically related to risk for social anxiety in girls, the lack of longitudinal data means that it is not possible to determine whether peer attachment plays a significant role in the development of social anxiety over time.

\section{Friendship Quality}

Of the 24 articles included in this review, 7 reported on the association between adolescent friendship and levels of social anxiety. In a longitudinal study exploring the role of friendship in the development of social anxiety in adolescents aged 10-18 years $(n=2194)$, Van Zalk and Van Zalk (2015) found that adolescents who were selected more as close friends experienced decreased social anxiety over time. Moreover, gender was found to be a significant moderator in this relationship, in that girls who were selected as a friend were less likely to experience an increase in social anxiety, relative to boys. This finding is consistent with the results of Starr and Davila (2008), who found that girls who reported having fewer close friends experienced higher levels of social anxiety, and suggests that being nominated as a friend serves as a stronger protective factor specifically for girls. Furthermore, Van Zalk and Van Zalk (2015) found that care by friends mediated the association between being selected as a friend and social anxiety, with adolescents who felt more cared for by their friends less likely to experience increased symptoms of social anxiety.

In an early longitudinal study of adolescents aged 12-14 years, Vernberg et al. (1992) conducted a prospective analysis of the bidirectional relationships between friendship quality (or rejection experiences) and social anxiety. They found that low companionship and intimacy in friendship predicted measures of social anxiety at 2 and 9 months. Although there were no significant gender interactions, social anxiety was also found to predict later companionship and intimacy in friendships, leading them to conclude that there was a reciprocal relationship between social anxiety and friendship quality in early adolescence for boys and girls.

In a more recent study of predictors of social anxiety and depression, La Greca and Harrison (2005) found that low positive and high negative friendship qualities were unique predictors of social anxiety in adolescents aged 14-19 years $(n=421)$. Despite studies finding that girls scored higher on positive friendship qualities (Greco and Morris 2005) than boys, and lower on negative interactions (La Greca and Harrison 2005), both Flanagan et al. (2008) and La Greca and Harrison (2005) found gender interactions to be non-significant. This indicates that the relationship between friendship quality and social anxiety was consistent between gender ( $\mathrm{La}$ Greca and Harrison 2005).

In contrast, La Greca and Lopez (1998) found gender differences in the relationship between friendship qualities and social anxiety, with a lack of close friendships significantly predicting general social anxiety in adolescent girls only. Similarly, in a study of preadolescent children aged 8-12 years $(n=333)$, Greco and Morris (2005) found that positive friendship qualities were significantly and negatively correlated with measures of social anxiety for girls only. Furthermore, negative friendship quality was found to moderate the relationship between social preference and social anxiety; girls with low social preference ratings experienced higher levels of social anxiety when their friendships were characterised by high negative friendship qualities. This indicates that girls who are less well accepted by their peers may be at increased risk of social anxiety when they experience difficulties in their friendships. Greco and Morris (2005) suggested that this gender difference may reflect the structure of boys' and girls' friendship groups, with girls tending to prefer a smaller and more intimate friendship group than boys.

\section{Peer Support}

A proportion of the studies in this review investigated the relationship between peer support and social anxiety $(n=6)$ with mixed findings. In a small scale longitudinal study, Grills-Taquechel et al. (2010) explored risk and resilience factors that predicted anxiety during transition to middle school. They asked adolescents, aged 11-15 years, to complete measures of social support and social anxiety at two time points and found that classmate and friendship support at age 11-12 years did not significantly predict social anxiety two years later. This indicates that, in this study, peer support was not related to adolescents' social anxiety during the transition to middle school.

However, a more recent study suggested that peer support may have an important role in adolescents' social anxiety by acting as a protective factor. In a longitudinal study involving 416 adolescents aged between 11 and 14 years, 
Cavanaugh and Buehler (2016) explored the association between cumulative and unique sources of social support, and adolescents' social anxiety. They found that cumulative support from parents, teachers and peers was associated with decreased anxiety in early adolescence, with this association being stronger for boys than girls. Peer support was also uniquely associated with decreased social anxiety in early adolescence, a finding that was consistent between genders. As peer relationships become increasingly important during adolescence, the authors suggested that adolescents may be more likely to draw on support from their peers in social situations due to their availability and the validation they provide.

Further evidence for the role of peer support was also provided by Tillfors et al. (2012), who found that social anxiety was significantly and negatively correlated with peer relationship support at baseline and one year later. Although this modest relationship was found for both genders, peer relationship support was not found to predict decreases in social anxiety over time. In a study of preadolescent girls only, Hutcherson and Epkins (2009) researched parent- and peer-related interpersonal correlates of social anxiety. They found that classmate support and close friend support, as reported by children themselves, were significantly and negatively correlated with social anxiety. After controlling for depression, only classmate support remained significant, with self-reported loneliness found to mediate the relationship between classmate support and social anxiety. Although the cross-sectional design of this research prevents causal pathways from being identified, the results indicate that increased classmate support may serve as a protective factor for social anxiety by reducing their internal distress and feelings of loneliness.

While research indicates that peer support is associated with social anxiety, no gender differences in this relationship have been found (Cavanaugh and Buehler 2016; Tillfors et al. 2012). In one of the earlier studies included in this review, La Greca and Lopez (1998) found that girls reported higher levels of social anxiety than boys, and more social support from their friends; the negative correlation between social anxiety and classmate support was stronger for girls. In addition, boys who experienced less support from their friends reported higher levels of general social avoidance and distress only, while girls were found to report higher levels of social anxiety across all areas. This indicates that although low levels of peer support may be involved in the development of social anxiety across both genders, friendship support may be differentially related to social anxiety in boys and girls.

One study by DeWit et al. (2011) explored the role of peer support further by investigating adolescents' perceptions of declining support during their transition to high school. In a twelve-month study involving 2616 Canadian adolescents aged $12-16$ years, they found that those who reported higher levels of peer support at 13-14 years of age were more likely to experience an increase in social anxiety-adolescents' perception of declining support was associated with increased social anxiety. There was no difference in the predictors of social anxiety between gender, however, girls perceived themselves as having higher levels of classmate support at 13-14 years, and a slower rate of decline in support over time compared with boys. Overall, this study suggested that peer support is an important protective factor, and if adolescents experience a greater decline in support over time, then they may be placed at increased risk of social anxiety.

\section{Peer Victimization}

One aspect of relationships that was considered by the majority of articles in this review $(n=14)$ was peer victimization, with many studies providing evidence of a significant association between this factor and social anxiety. For example, in their cross-sectional study exploring peer relations in early adolescence, Flanagan et al. (2008) found that peer victimization made a significant and unique contribution to social anxiety, with this relationship being stronger for boys than girls. Although positive associations were also found by Tillfors et al. (2012), they reported that the association between peer victimization and social anxiety was stronger for adolescent girls than boys, at one-year follow-up. While exploring gender differences in the association between victimization experiences and psychosocial wellbeing in Dutch preadolescents aged 8-12 years $(n=2859)$, van der Ploeg et al. (2015) found that although social anxiety was significantly associated with a higher number of bullies in boys, it was more strongly associated with frequency of victimization in girls.

Several of the articles included in this review provided evidence regarding the relationship between types of victimization and social anxiety. Overt victimization refers to physical harm or associated threats (Storch and MasiaWarner 2004), and relational victimization involves being harmed through manipulation or damage to interpersonal relationships, such as spreading rumours or being excluded by peers (Crick and Grotpeter 1996). In a study examining the relationship between different types of bullying experiences and social anxiety in Taiwanese adolescents $(n=5527)$ aged 11-18 years, Yen et al. (2013) found that victims of verbal and relational bullying, and 'physical bullying and belongings snatch', reported more severe social anxiety than non-victims. They found that perpetrators of verbal and relational bullying also reported more severe social anxiety than non-perpetrators, which suggests that although victims of bullying may be at increased risk of developing social anxiety, heightened social anxiety may also be associated with 
an increased risk of adolescents verbally bullying their peers. Gender did not moderate the association between involvement in bullying and social anxiety.

Evidence regarding the relationship between overt victimization and social anxiety was mixed. In a longitudinal study designed to examine the role of school connectedness as a moderator in the relationship between victimization and later adjustment difficulties, Loukas and Pasch (2013) found that overt and relational victimization at baseline was positively associated with concurrent and later social anxiety, in boys and girls. However, after controlling for baseline social anxiety and gender, only overt victimization was found to uniquely contribute to later social anxiety. Gender did not moderate the effect, indicating that overt victimization was associated with similar increases in social anxiety in boys and girls.

Despite reporting a positive association between overt victimization and social anxiety, the results of La Greca and Harrison (2005) contrast with the above findings in that overt victimization did not make a significant and unique contribution to social anxiety, when considered alongside relational victimization. Similarly, Siegel et al. (2009) reported that although overt victimization was significantly correlated with social anxiety at baseline and 2 months $(n=228)$, it did not uniquely predict social anxiety concurrently or over time. This suggests that overt victimization may not contribute to social anxiety in older adolescents, with both studies involving comparable populations of adolescents aged between 14 and 19 years.

To further explore the prospective links between victimization and adolescent social anxiety, Storch et al. (2005) conducted longitudinal research involving high-school students aged 13-15 years $(n=198)$. While concurrent associations were found, overt victimization at baseline did not predict later social anxiety in boys or girls after controlling for initial levels of social anxiety. Although this is consistent with the findings of Siegel et al. (2009), it contrasts with the work of Loukas and Pasch (2013). One possible explanation for these conflicting findings could therefore be that, as the latter study involved younger participants aged 10-14 years, overt victimization predicts increases in social anxiety in early adolescents only.

Research has also explored the association between overt victimization and specific variables of social anxiety. In a series of cross-sectional studies published by the same lead author (Storch et al. 2003a; Storch and Masia-Warner 2004; Storch et al. 2003b), the results found that overt victimization was significantly and positively associated with fear of negative evaluation, social avoidance and distress of new situations, and general social avoidance, with medium to large effect sizes reported (Storch et al. 2003b). Analysis of results by gender found that overt victimization was a significant predictor of all variables of social anxiety in adolescent girls
( $\mathrm{n}=186,10-13$ years), but did not predict social avoidance of new situations for boys (Storch et al. 2003b). Therefore, although overt victimization was found to be a significant predictor of social anxiety across genders, it may be uniquely linked to social avoidance in adolescent girls.

Cross-sectional studies have consistently found a significant association between relational victimization and social anxiety. For example, La Greca and Harrison (2005) found that relational victimization was positively correlated with, and uniquely predicted, social anxiety in boys and girls. Likewise, Storch et al. (2003b) found that relational victimization in Hispanic and African American preadolescents was significantly and positively correlated with social anxiety measures. However, after controlling for overt victimization, the results indicated that relational victimization was uniquely associated with fear of negative evaluation and general social avoidance in girls only.

Further evidence of the association between relational victimization and social anxiety was found by Storch and Masia-Warner (2004). In their cross-sectional study involving adolescent girls $(n=561)$ aged $13-17$ years, they found that relational victimization was positively correlated with measures of social anxiety and, after controlling for prosocial behaviour, uniquely predicted all individual variables on the Social Anxiety Scale for Adolescents. Girls who reported higher levels of relational victimization experienced increased social anxiety, relative to non-victims and victims of overt victimization only, leading them to suggest that relational victimization may place girls at increased risk of later adjustment difficulties. Furthermore, although participants were recruited from a school-based non-clinical population, Storch and Masia-Warner (2004) found that girls experiencing relational victimization reported levels of social anxiety at or near clinically significant levels.

Longitudinal studies provided further evidence of the role of relational victimization in the development of social anxiety in adolescence. A recent study by Hamilton et al. (2016) involving adolescents aged 12-13 years, explored the relationship between relational victimization and social anxiety over three time points, each approximately 9 months apart. They found that relational victimization significantly predicted social anxiety at 9 months, which further predicted social anxiety at 18 months. Although this indicates that relational victimization may have a direct influence on social anxiety over time, Hamilton et al. (2016) also found an indirect effect through its association with symptoms of depression at 9 months. This suggests that comorbid mental health difficulties may further exacerbate levels of social anxiety. However, in contrast with aforementioned studies, Hamilton et al. (2013) and Storch et al. (2005) found that baseline relational victimization did not predict increases in social anxiety over time. Little explanation has been offered for these conflicting findings but given the similarity in the 
measures used and population age, it is possible that the results are due to the increased sample size recruited by Hamilton et al. (2016).

In an early longitudinal study involving 68 young adolescents aged 12-14 years, Vernberg et al. (1992) also explored the prospective links between relational victimization and social anxiety. They found that while peer exclusion at the beginning of the academic year predicted increased fear of negative evaluation 2 months later, only girls experienced increased social avoidance of new situations. On-going experiences of peer exclusion between 2 and 9 months also predicted increased social anxiety across both genders. Rejection by peers during the first few months of the academic year may therefore increase girls' fear of negative evaluation and social avoidance of new situations, which, over time, has a broader impact on general social anxiety.

Further studies have found mixed results regarding gender differences. While Siegel et al. (2009) reported that gender did not moderate the concurrent relationship between relational victimization and social anxiety, this was not the case over time. Relational victimization at baseline significantly predicted increased social anxiety for girls, but not boys. Similarly, in their study of peer victimization in Finnish adolescents ( $n=2070,15-17$ years), Ranta et al. (2013) found that relational victimization at age 15 was independently associated with social anxiety at age 17 in girls, but not boys, after controlling for baseline social anxiety and victimization. Specifically, girls who experienced relational victimization at age 15 had a six-fold increase in risk of developing social anxiety at age 17 . Overall, while the findings for overt victimization are mixed, research suggests that relational victimization may be a stronger predictor of social anxiety and social avoidance in adolescent girls.

\section{A Developmental Pathway Model to Social Anxiety in Girls}

This systematic review outlined risk factors that were common to the development of social anxiety across genders, as well as those that were uniquely linked to girls. Based on the body of evidence a framework was developed to capture both generic and gender-specific risk for the development of social anxiety in adolescence (see Fig. 2). The framework highlights that, while some aspects of peer relations may be risk factors for the development of social anxiety in adolescent girls, other elements may serve as important protective factors.

\section{Discussion}

As girls are at increased risk of social anxiety in adolescence relative to boys, a clearer understanding of risk and protective factors in terms of how social anxiety develops, and the role of peer relationships in this regard, is important in informing future empirical research and clinical intervention. To this end, the aim of this systematic review was to explore the literature on the role of peers in the development of social anxiety in adolescent girls and, specifically,

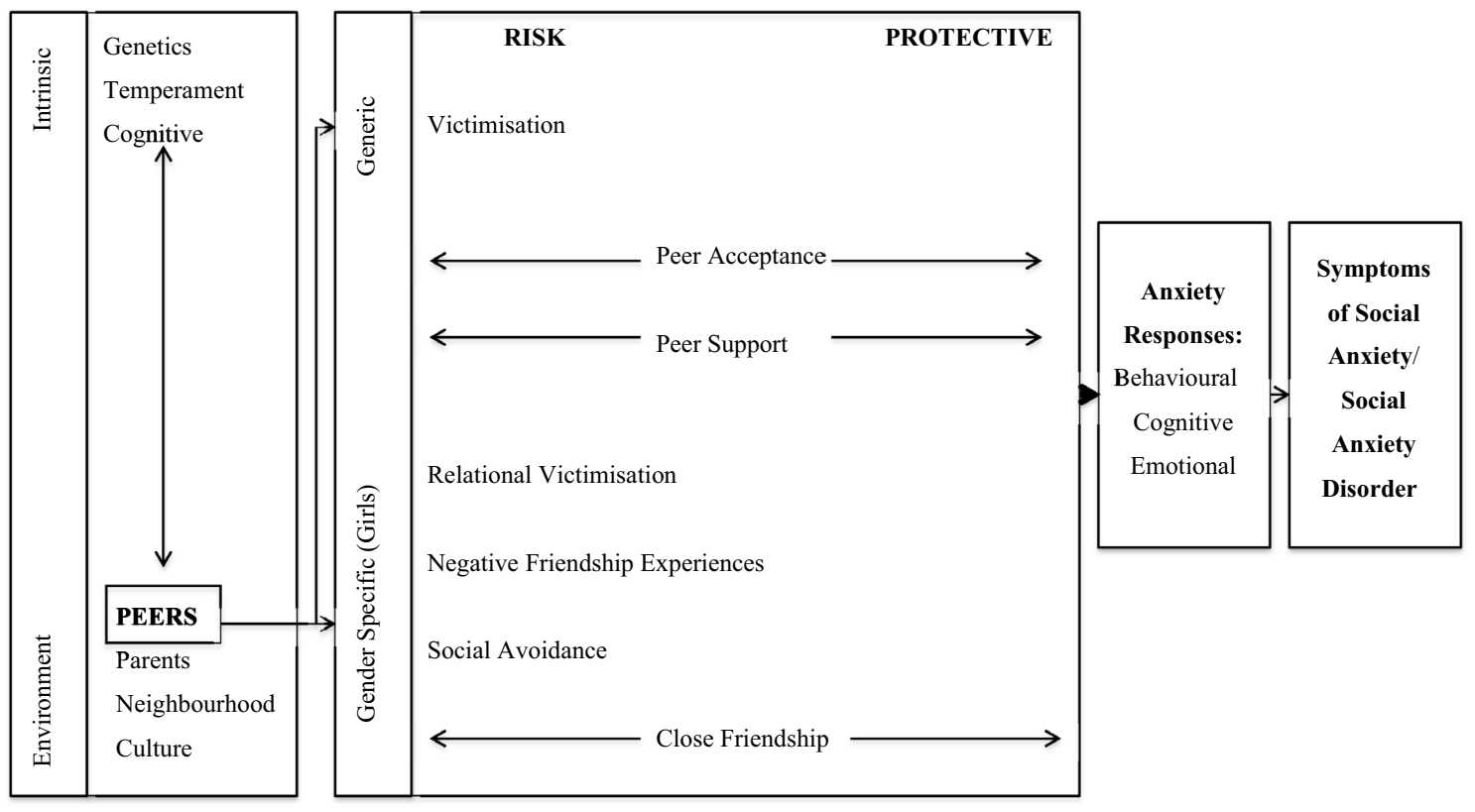

Fig. 2 Developmental framework for the risk of social anxiety disorder in adolescent girls via negative peer relationships 
to further our understanding of peer-related risk factors and gender-specific pathways. This review found that girls are at increased risk of social anxiety if they have limited numbers of close friendships, and experience negative friendships or relational bullying. Conversely, having a close friend may serve as a protective factor for girls, highlighting the importance of positive social relationships in this developmental stage. To further our understanding of peer-related risk factors, a framework has been proposed to collate both generic and gender-specific risks.

\section{Peer Victimization and Social Anxiety}

The evidence base suggests a significant association between peer victimization and social anxiety across both genders. While some studies found that the association was stronger for boys than girls (Flanagan et al. 2008), others found that it was stronger for girls over time (Tillfors et al. 2012). More specifically, the findings on the association between overt victimization and social anxiety were mixed. A limited amount of evidence was found to suggest that overt victimization predicted social anxiety in younger adolescents, both for boys and girls (Loukas and Pasch 2013), but did not contribute to social anxiety over time for older adolescents (Siegel et al. 2009; Storch et al. 2005). In addition, although some studies suggested that the association between relational victimization and social anxiety was consistent across genders (Hamilton et al. 2013, 2016), others found that relational victimization placed girls at increased risk of developing social anxiety during adolescence relative to boys (Ranta et al. 2013; Siegel et al. 2009; Storch and Masia-Warner 2004).

Research has shown that while low peer acceptance predicted social anxiety in adolescence, its effects were not unique to girls (e.g. Grills-Taquechel et al. 2010). Adolescents who experienced higher levels of peer acceptance had lower levels of social anxiety, which indicates that peer acceptance may serve as an important protective factor against the development of social anxiety in boys and girls. Research on the role of peer support was also mixed. While two studies found that peer support did not predict social anxiety over time (Grills-Taquechel et al. 2010; Tillfors et al. 2012), others found that peer support was negatively associated with decreased social anxiety across both genders (Cavanaugh and Buehler 2016). However, research found that this association was stronger for girls than boys, with girls reporting higher levels of support from their friends, as well as increased social anxiety (La Greca and Lopez 1998). Even when controlling for depression, this negative correlation was found to remain significant (Hutcherson and Epkins 2009). Peer support may therefore help to protect adolescent girls from the development of social anxiety by reducing loneliness and distress. Furthermore, research suggested that friendship support may have a broader impact on girls' social anxiety than boys (La Greca and Lopez 1998) and, where they experienced a decline in classmate support, girls were again placed at increased risk (DeWit et al. 2011).

Although the research in this review found a significant negative association between friendship quality and social anxiety, evidence on gender differences was mixed. While some studies found no significant difference (e.g. Flanagan et al. 2008), others reported that a lack of close friendships significantly predicted social anxiety in adolescent girls but not boys (La Greca and Lopez 1998). In addition, whereas negative friendship qualities were found to be consistent across genders, positive friendship quality was significantly and negatively associated with social anxiety in girls only (Greco and Morris 2005). Girls with low levels of peer acceptance were found to be at increased risk of developing social anxiety when their friendships were high in negative friendship qualities (Greco and Morris 2005). Therefore, although positive and close friendships may serve as a protective factor, research has found that where friendships are lacking or are characterised by negative qualities, girls may feel more isolated and be at greater risk of developing social anxiety.

As friendship quality was significantly associated with levels of social anxiety, this may also account for why being selected as a friend was found to be an important protective factor for girls. Receiving fewer friendship nominations was found to be a significant predictor of social anxiety over time, with gender moderating this relationship; girls who were selected as friends had a reduced likelihood of experiencing increased social anxiety (Van Zalk and Van Zalk 2015). This suggests that adolescents with smaller friendship networks are at increased risk of developing social anxiety. As girls typically have smaller friendship groups than boys, this could help account for the importance of friendship on the development of social anxiety in girls, as well as the increased impact when they encounter relationship difficulties.

This review of the literature provides key implications for wider practice. A number of different peer-related factors have been discussed which have a significant association with social anxiety in adolescent girls, including peer acceptance, friendship quality, peer support and victimization. Research indicates that proactive and preventative intervention programmes are needed to help protect young people from the development of social anxiety by increasing their social interaction skills and improving the quality of their peer relationships. Evidence suggests that interventions are needed that promote positive friendship experiences, while also providing girls with problem solving skills to help them manage and resolve negative friendship experiences.

In addition to providing direct one-to-one or small group intervention programmes, it is also important to work at a 
systemic level by raising awareness of these key risk and protective factors in schools. As pre- and early adolescence is a time of particular risk for the development of social anxiety, it is essential that school staff are able to recognize girls who may be at increased risk due to limited close friendships, negative friendship experiences or high relational victimization. Given that research has found that girls who experience relational victimization at age 15 have a six fold increase in risk of developing social anxiety by age 17 (Ranta et al. 2013), this demonstrates the importance of implementing anti-bullying programmes and raising the awareness of relational bullying in girls, including "friendship manipulation or social exclusion" (Hamilton et al. 2013, p. 334).

\section{Limitations and Implications for Future Research}

Most studies in this review used self-reported measures of social anxiety and peer relationships, which could be subject to reporter bias (Hamilton et al. 2013; Storch et al. 2003b) and inflated findings resulting from shared method variance (Loukas and Pasch 2013; Storch and Masia-Warner 2004; Storch et al. 2005; van der Ploeg et al. 2015). Although it has been suggested that internal states of anxiety may not be apparent to outside observers (Siegel et al. 2009) and that self-reports may be the most accurate form of measurement (Tillfors et al. 2012), future research would likely benefit from supplementary methods, such as observations, interviews and parent-report, to provide further data for triangulation.

Another limitation of many of the studies included in this review was the cross-sectional design of the research. Although this design can provide an indication of significant associations between a wide variety of variables, it does not provide any indication of the direction of the effect (e.g. Hutcherson and Epkins 2009; La Greca and Lopez 1998). Therefore, although many of the cross-sectional studies found that peer factors were significantly correlated with increased social anxiety, it is impossible to determine the extent to which particular peer variables contributed to the development of social anxiety. While longitudinal studies allow for the exploration of causal pathways, insufficient time points may be more prone to error, and limit the examination of interaction effects between variables (GrillsTaquechel et al. 2010; Loukas and Pasch 2013). Future longitudinal research should therefore explore the development of social anxiety over a longer timeframe but with more frequent sampling.

Most studies included in this review were conducted in the USA. Although this can provide a heterogeneous sample of participants, many of the studies included predominantly Caucasian participants from middle-class socio-economic status backgrounds (e.g., Greco and Morris 2005; Storch et al. 2003a). This may limit the generalizability of findings and suggests that further research is required in more ethnically and socially diverse populations, as young people within these populations may be exposed to greater risk factors (e.g. discrimination) (Cavanaugh and Buehler 2016). In addition, as the studies in this review relied on community-based populations, it is possible that young people who experienced higher levels of distress may have been less willing to participate in the research (Flanagan et al. 2008). Furthermore, in one study, participants in the highest $10 \%$ of scores on measures of social anxiety were invited to participate in an intervention and were thus excluded from the research (Storch et al. 2005).

In addition, the research in this review was of a quantitative nature, reflecting the wider research in this field. Therefore, future research would likely benefit from the use of qualitative or mixed method approaches to investigate the perspectives of young girls who are identified as being at risk of developing social anxiety. In particular, a more indepth understanding of how peer difficulties develop, and strategies used by individuals and schools that promote positive peer relationships, would help to illuminate some of the methods that may serve as protective factors.

Finally, this review is not in itself without limitations. In particular, the systematic search was limited to articles that were in peer reviewed academic journals and the gray literature (e.g., unpublished research, doctoral theses, conference papers) was not consulted, which may highlight a publication bias. Moreover, the search was limited to the English language, potentially missing published research in other languages not spoken by the researchers.

\section{Conclusion}

Girls are at elevated risk of developing anxiety disorders relative to boys across development. The aim of this review was to collate the available empirical literature to further our understanding of risk factors in the development of social anxiety that are common to both genders, and specific to adolescent girls. Following a systematic search of the literature, this review explored the role of peer relationships in the development of social anxiety in adolescent girls. The evidence indicated that there are a number of interacting peerrelated risk and protective factors that influence the development of social anxiety. Several risk factors were common across boys and girls, including peer acceptance, peer support and victimization. Other unique factors placed girls at increased risk of social anxiety and included limited close friendships, negative friendship experiences and relational victimization. The review also highlighted the importance of friendship as a protective factor for adolescent girls in the development of social anxiety. In attempting to further our 
understanding of peer-related risk factors, this review has proposed a framework to capture these generic and genderspecific risks and has considered the implications for future research and practice.

Acknowledgements This work forms part of the first author's Doctorate in Educational Psychology thesis.

Authors' Contributions LP conceived of the study, participated in the design of the study, planned the protocol, conducted the primary literature searches, quality assessed the papers, drafted the findings, and wrote the first draft of the manuscript; JH conceived of the study, participated in the design of the study, planned the protocol, interpreted the findings, and commented on drafts of the manuscript; HK conceived of the study, participated in the design of the study, planned the protocol, interpreted the findings, and helped to draft the manuscript. All authors contributed to and approved the final manuscript.

\section{Compliance with Ethical Standards}

Conflicts of interest All authors declare that they have no conflicts of interest.

Open Access This article is distributed under the terms of the Creative Commons Attribution 4.0 International License (http://creativeco mmons.org/licenses/by/4.0/), which permits unrestricted use, distribution, and reproduction in any medium, provided you give appropriate credit to the original author(s) and the source, provide a link to the Creative Commons license, and indicate if changes were made.

\section{References}

American Psychiatric Association. (2013). Diagnostic and statistical manual of mental disorders (5th ed.). Arlington, VA: American Psychiatric Association.

Armsden, G. C., \& Greenberg, M. T. (1987). The inventory of parent and peer attachment: Individual differences and their relationship to psychological well-being in adolescence. Journal of Youth and Adolescence, 16(5), 427-454. https://doi.org/10.1007/BF022 02939.

Baker, J. R., \& Hudson, J. L. (2015). Children with social phobia have lower quality friendships than children with other anxiety disorders. Anxiety Stress and Coping, 28(5), 500-513. https://doi. org/10.1080/10615806.2014.978863.

Beesdo, K., Bittner, A., Pine, D. S., Stein, M. B., Höfler, M., Lieb, R., et al. (2007). Incidence of social anxiety disorder and the consistent risk for secondary depression in the first three decades of life. Archives of General Psychiatry, 64(8), 903-912. https://doi. org/10.1001/archpsyc.64.8.903.

Beidel, D. C., Turner, S. M., \& Morris, T. L. (1995). A new inventory to assess childhood social anxiety and phobia: The social phobia and anxiety inventory for children. Psychological Assessment, 7, 73-79. https://doi.org/10.1037/1040-3590.7.1.73.

Beidel, D. C., Turner, S. M., \& Morris, T. L. (1998). Social phobia and anxiety inventory for children. North Tonawanda, NY: MultiHealth Systems.

Berndt, T. J., \& Perry, T. B. (1986). Children's perceptions of friendships as supportive relationships. Developmental Psychology, 22(5), 640-648. https://doi.org/10.1037/0012-1649.22.5.640.

Black, J. J., Clark, D. B., Martin, C. S., Kim, K. H., Blaze, T. J., Creswell, K. G., et al. (2015). Course of alcohol symptoms and Social Anxiety Disorder from adolescence to young adulthood. Alcoholism, Clinical and Experimental Research, 39(6), 1008-1015.

Bögels, S. M., Van Oosten, A., Muris, P., \& Smulders, D. (2001). Familial correlates of social anxiety in children and adolescents. Behaviour Research and Therapy, 39(3), 273-287. https://doi. org/10.1016/S0005-7967(00)00005-X.

Bolton, J. M., Cox, B. J., Afifi, T. O., Enns, M. W., Bienvenu, O. J., \& Sareen, J. (2008). Anxiety disorders and risk for suicide attempts: Findings from the Baltimore epidemiologic catchment area follow-up study. Depression and Anxiety, 25(6), 477-481. https:// doi.org/10.1002/da.20314.

Bracik, J., Krysta, K., \& Zaczek, A. (2012). Impact of family and school environment on the development of Social Anxiety Disorder: A questionnaire study. Psychiatria Danubina, 24(1), S125-S127.

Brook, C. A., \& Schmidt, L. A. (2008). Social anxiety disorder: A review of environmental risk factors. Neuropsychiatric Disease and Treatment, 4(1), 123-143.

Buckner, J. D., Schmidt, N. B., Lang, A. R., Small, J. W., Schlauch, R. C., \& Lewinsohn, P. M. (2008a). Specificity of social anxiety disorder as a risk factor for alcohol and cannabis dependence. Journal of Psychiatric Research, 42(3), 230-239. https://doi. org/10.1016/j.jpsychires.2007.01.002.

Buckner, J. D., Timpano, K. R., Zvolensky, M. J., Sachs-Ericsson, N., \& Schmidt, N. B. (2008b). Implications of comorbid alcohol dependence among individuals with social anxiety disorder. Depression and Anxiety, 25(12), 1028-1037. https://doi. org/10.1002/da.20442.

Cavanaugh, A. M., \& Buehler, C. (2016). Adolescent loneliness and social anxiety: The role of multiple sources of support. Journal of Social and Personal Relationships, 33(2), 149-170. https:// doi.org/10.1177/0265407514567837.

Clauss, J. A., \& Blackford, J. U. (2012). Behavioral inhibition and risk for developing social anxiety disorder: A meta-analytic study. Journal of the American Academy of Child and Adolescent Psychiatry, 51(10), 1066-1075. https://doi.org/10.1016/j. jaac.2012.08.002.

Connor, K. M., Davidson, J. R. T., Churchill, L. E., Sherwood, A., Foa, E., \& Weisler, R. H. (2000). Psychometric properties of the Social Phobia Inventory (SPIN): New self-rating scale. The British Journal of Psychiatry, 176(4), 379-386. https://doi. org/10.1192/bjp.176.4.379.

Crick, N. R., \& Grotpeter, J. K. (1996). Children's treatment by peers: Victims of relational and overt aggression. Development and Psychopathology, 8(2), 367. https://doi.org/10.1017/S095457940 0007148.

Davidson, J. R., Hughes, D. L., George, L. K., \& Blazer, D. G. (1993). The epidemiology of social phobia: Findings from the Duke Epidemiological Catchment Area Study. Psychological Medicine, 23(3), 709-718. https://doi.org/10.1017/S0033291700025484.

Demir, T., Karacetin, G., Eralp Demir, D., \& Uysal, O. (2013). Prevalence and some psychosocial characteristics of social anxiety disorder in an urban population of Turkish children and adolescents. European Psychiatry, 28(1), 64-69. https://doi.org/10.1016/j. eurpsy.2011.12.003.

DeWit, D. J., Chandler-Coutts, M., Offord, D. R., King, G., McDougall, J., Specht, J., et al. (2005). Gender differences in the effects of family adversity on the risk of onset of DSM-III-R social phobia. Journal of Anxiety Disorders, 19(5), 479-502. https://doi. org/10.1016/j.janxdix.2004.04.010.

DeWit, D. J., Karioja, K., Rye, B. J., \& Shain, M. (2011). Perceptions of declining classmate and teacher support following the transition to high school: Potential correlates of increasing student mental health difficulties. Psychology in the Schools, 48(6), 556-572. https://doi.org/10.1002/pits.20576. 
Downs, S. H., \& Black, N. (1998). The feasibility of creating a checklist for the assessment of the methodological quality both of randomised and non-randomised studies of health care interventions. Journal of Epidemiology and Community Health, 52(6), 377-384. https://doi.org/10.1136/jech.52.6.377.

Dubow, E. F., \& Ullman, D. G. (1989). Assessing social support in elementary school children: The survey of children's social support. Journal of Clinical Child Psychology, 18(1), 52-64. https ://doi.org/10.1207/s15374424jccp1801_7.

Epkins, C. C., \& Heckler, D. R. (2011). Integrating etiological models of Social Anxiety and depression in youth: Evidence for a cumulative interpersonal risk model. Clinical Child and Family Psychology Review, 14(4), 329-376. https://doi.org/10.1007/ s10567-011-0101-8.

Essau, C. A., Lewinsohn, P. M., Olaya, B., \& Seeley, J. R. (2014). Anxiety disorders in adolescents and psychosocial outcomes at age 30. Journal of Affective Disorders, 163, 125-132. https://doi. org/10.1016/j.jad.2013.12.033.

Fehm, L., Pelissolo, A., Furmark, T., \& Wittchen, H. U. (2005). Size and burden of social phobia in Europe. European Neuropsychopharmacology, 15(4), 453-462. https://doi.org/10.1016/j.euron euro.2005.04.002.

Festa, C. C., \& Ginsburg, G. S. (2011). Parental and peer predictors of social anxiety in youth. Child Psychiatry and Human Development, 42(3), 291-306. https://doi.org/10.1007/s1057 8-011-0215-8.

Flanagan, K. S., Erath, S. A., \& Bierman, K. L. (2008). Unique associations between peer relations and social anxiety in early adolescence. Journal of Clinical Child and Adolescent Psychology, 37(4), 759-769. https://doi.org/10.1080/15374410802359700.

Fox, N. A. (2010). Factors contributing to the emergence of anxiety among behaviorally inhibited children: The role of attention. In H. Gazelle \& K. H. Rubin (Eds.), Social anxiety in childhood: Bridging developmental and clinical perspectives (Vol. 127, pp. 33-49). San Francisco: Jossey-Bass.

Furman, W., \& Buhrmester, D. (1985). Children's perceptions of the personal relationships in their social networks. Developmental Psychology, 21(6), 1016-1024. https://doi. org/10.1037/0012-1649.21.6.1016.

Furman, W., \& Buhrmester, D. (1992). Age and sex differences in perceptions of networks of personal relationships. Child Development, 63(1), 103-115.

Ginsburg, G. S., La Greca, A. M., \& Silverman, W. K. (1998). Social anxiety in children with anxiety disorders: Relation with social and emotional functioning. Journal of Abnormal Child Psychology, 26(3), 175-185. https://doi.org/10.1023/A:1022668101048.

Greco, L. A., \& Morris, T. L. (2002). Paternal child-rearing style and child social anxiety: Investigation of child perceptions and actual father behavior. Journal of Psychopathology and Behavioral Assessment, 24(4), 259-267. https://doi.org/10.1023/A:10207 79000183.

Greco, L. A., \& Morris, T. L. (2005). Factors influencing the link between social anxiety and peer acceptance: Contributions of social skills and close friendships during middle childhood. Behavior Therapy, 36(2), 197-205. https://doi.org/10.1016/ S0005-7894(05)80068-1.

Green, H., McGinnity, A., Meltzer, H., Ford, T., \& Goodman, R. (2005). Mental health of children and young people in Great Britain, 2004. Basingstoke: Palgrave Macmillan.

Gren-Landell, M., Björklind, A., Tillfors, M., Furmark, T., Svedin, C., \& Andersson, G. (2009). Evaluation of the psychometric properties of a modified version of the Social Phobia Screening Questionnaire for use in adolescents. Child and Adolescent Psychiatry and Mental Health, 3, 36. https://doi. org/10.1186/1753-2000-3-36.
Grills-Taquechel, A. E., Norton, P., \& Ollendick, T. H. (2010). A longitudinal examination of factors predicting anxiety during the transition to middle school. Anxiety Stress and Coping, 23(5), 493-513. https://doi.org/10.1080/10615800903494127.

Hamilton, J. L., Potter, C. M., Olino, T. M., Abramson, L. Y., Heimberg, R. G., \& Alloy, L. B. (2016). The temporal sequence of social anxiety and depressive symptoms following interpersonal stressors during adolescence. Journal of Abnormal Psychology, 44(3), 495-509. https://doi.org/10.1007/s1080 2-015-0049-0.

Hamilton, J. L., Shapero, B. G., Stange, J. P., Hamlat, E. J., Abramson, L. Y., \& Alloy, L. B. (2013). Emotional maltreatment, peer victimization, and depressive versus anxiety symptoms during adolescence: hopelessness as a mediator. Journal of Clinical Child \& Adolescent Psychology, 42(January), 332-347. https:// doi.org/10.1080/15374416.2013.777916.

Harter, S. (1985). Manual for the social support scale for children. Denver, CO: University of Denver.

Harter, S. (1988). Manual for the self-perception profile for adolescents. Denver, CO: University of Denver.

Hutcherson, S. T., \& Epkins, C. C. (2009). Differentiating parent- and peer-related interpersonal correlates of depressive symptoms and social anxiety in preadolescent girls. Journal of Social and Personal Relationships, 26(6-7), 875-897. https://doi. org/10.1177/0265407509345654.

Kessler, R. C., Aguilar-Gaxiola, S., Alonso, J., Chatterji, S., Lee, S., Ormel, J., ... Wang, P. S. (2009). The global burden of mental disorders: An update from the WHO World Mental Health (WMH) surveys. Epidemiologia E Psichiatria Sociale, 18(1), 23-33. https://doi.org/10.1017/s1121189x00001421

Kessler, R. C., Berglund, P., Demler, O., Jin, R., Merikangas, K. R., $\&$ Walters, E. E. (2005a). Lifetime prevalence and age-of-onset distributions of DSM-IV disorders in the National Comorbidity Survey Replication. Archives of General Psychiatry, 62(June), 593-602. https://doi.org/10.1001/archpsyc.62.6.593.

Kessler, R. C., Chiu, W. T., Demler, O., \& Walters, E. E. (2005b). Prevalence, severity, and comorbidity of 12-month DSM-IV disorders in the National Comorbidity Survey Replication. Archives of General Psychiatry, 62(6), 617. https://doi.org/10.1001/archp syc.62.6.617.

Kessler, R. C., Petukhova, M., Sampson, N. A., Zaslavsky, A. M., \& Wittchen, H.-U. (2012). Twelve-month and lifetime prevalence and lifetime morbid risk of anxiety and mood disorders in the United States. International Journal of Methods in Psychiatric Research, 21(3), 169-184. https://doi.org/10.1002/mpr.1359.

Khan, A., Leventhal, R. M., Khan, S., \& Brown, W. A. (2002). Suicide risk in patients with anxiety disorders: A meta-analysis of the FDA database. Journal of Affective Disorders, 68(2-3), 183-190. https://doi.org/10.1016/S0165-0327(01)00354-8.

Kujawa, A., Arfer, K. B., Klein, D. N., \& Proudfit, G. H. (2014). Electrocortical reactivity to social feedback in youth: a pilot study of the Island Getaway task. Developmental Cognitive Neuroscience., 10, 140-147. https://doi.org/10.1016/j.den.2014.08.008.

La Greca, A. M. (1999). Manual for the Social Anxiety Scales. Miami, FL: Author.

La Greca, A. M., Dandes, S. K., Wick, P., Shaw, K., \& Stone, W. L. (1988). Development of the Social Anxiety Scale for Children: Reliability and concurrent validity. Journal of Clinical Child Psychology. https://doi.org/10.1207/s15374424jccp1701_11.

La Greca, A. M., \& Harrison, H. M. (2005). Adolescent peer relations, friendships, and romantic relationships: Do they predict social anxiety and depression? Journal of Clinical Child \& Adolescent Psychology, 34(1), 49-61. https://doi.org/10.1207/s15374424j ccp3401_5.

La Greca, A. M., \& Lopez, N. (1998). Social anxiety among adolescents: Linkages with peer relations and friendships. 
Journal of Abnormal Child Psychology, 26(2), 83-94. https:// doi.org/10.1023/A:1022684520514.

La Greca, A. M., \& Stone, W. L. (1993). Social Anxiety Scale for Children-Revised: Factor structure and concurrent validity. Journal of Clinical Child Psychology, 22(1), 17-27. https://doi. org/10.1207/s15374424jccp2201_2.

Lansford, J. E., \& Parker, J. G. (1999). Children's interactions in triads: Behavioral profiles and effects of gender and patterns of friendships among members. Developmental Psychology, 35(1), 80-93. https://doi.org/10.1037/0012-1649.35.1.80.

Lieb, R., Wittchen, H. U., Höfler, M., Fuetsch, M., Stein, M. B., \& Merikangas, K. R. (2000). Parental psychopathology, parenting styles, and the risk of social phobia in offspring: a prospectivelongitudinal community study. Archives of General Psychiatry, 57(9), 859-866. https://doi.org/10.1001/archpsyc.57.9.859.

Loukas, A., \& Pasch, K. E. (2013). Does school connectedness buffer the impact of peer victimization on early adolescents' subsequent adjustment problems? The Journal of Early Adolescence, 33(2), 245-266. https://doi.org/10.1177/0272431611435117.

Lu, A., Tian, H., Yu, Y., Feng, Y., Hong, X., \& Yu, Z. (2015). Peer attachment and social anxiety: Gender as a moderator across deaf and hearing adolescents. Social Behavior and Personality, 43(2), 231-240. https://doi.org/10.2224/sbp.2015.43.2.231.

March, J. (1997). Multidimensional Anxiety scale for children. North Tonawanda, NY: Multi-Health Systems.

Masten, A. S. (2014). Ordinary magic: Resilience in development. New York: The Guilford Press.

Masten, A. S., \& Cicchetti, D. (2010). Developmental cascades. Development and Psychopathology, 22(2010), 491-495. https://doi. org/10.1017/S0954579410000222.

McLean, C. P., Asnaani, A., Litz, B. T., \& Hofmann, S. G. (2011). Gender differences in anxiety disorders: Prevalence, course of illness, comorbidity and burden of illness. Journal of Psychiatric Research, 45(8), 1027-1035. https://doi.org/10.1016/j.jpsychires .2011.03.006.

Merikangas, K., Hep, J., Burstein, M., Swanson, S., Avenevoli, S., Cui, L., Benejet, C., ... Swendsen, J. (2010). Lifetime prevalence of mental disorders in U.S. adolescents: Results from the National Comorbidity Survey Replication-Adolescent Supplement (NCS-A). Journal of American Academy of Child and Adolescent Psychiatry, 49(10), 980-989. https://doi.org/10.1016/j. jaac.2010.05.017.

Möller, E. L., Nikolić, M., Majdandžić, M., \& Bögels, S. M. (2016). Associations between maternal and paternal parenting behaviors, anxiety and its precursors in early childhood: A meta-analysis. Clinical Psychology Review, 45, 17-33. https://doi.org/10.1016/j. cpr.2016.03.002.

National Institute for Health and Care Excellence. (2013, May). Social anxiety disorder: Recognition, assessment and treatment (pp. 1-44). Retrieved from www.papers3://publication/uuid/CDC13 819-E3F7-4DA7-8A8D-609AB8EEF993.

National Institute of Health. (2014). Quality Assessment Tool for observational cohort and cross-sectional studies. Retrieved from https://www.nhlbi.nih.gov/health-pro/guidelines/in-develop/cardi ovascular-risk-reduction/tools/cohort.

Nelemans, S. A., Hale, W. W., Raaijmakers, Q. A. W., Branje, S. J. T., van Lier, P. A. C., \& Meeus, W. H. J. (2016). Longitudinal associations between social anxiety symptoms and cannabis use throughout adolescence: the role of peer involvement. European Child and Adolescent Psychiatry, 25(5), 483-492. https://doi. org/10.1007/s00787-015-0747-8.

Ollendick, T. H., \& Hirshfeld-Becker, D. R. (2002). The developmental psychopathology of social anxiety disorder. Biological Psychiatry, 51(1), 44-58. https://doi.org/10.1016/S0006-3223(01)01305 -1 .
Olweus, D. (1996). The revised Olweus bully/victim questionnaire. Bergen: Research Center for Health Promotion (HEMIL Center), University of Bergen.

Parker, J. G., \& Asher, S. R. (1993). Friendship and friendship quality in middle childhood: Links with peer group acceptance and feelings of loneliness and social dissatisfaction. Developmental Psychology, 29(4), 611-621. https://doi. org/10.1037/0012-1649.29.4.611.

Parker, J. G., \& Herrera, C. (1996). Interpersonal processes in friendship: A comparison of abused and nonabused children's experiences. Developmental Psychology, 32(6), 1025-1038. https://doi. org/10.1037/0012-1649.32.6.1025.

Polanczyk, G. V., Salum, G. A., Sugaya, L. S., Caye, A., \& Rohde, L. A. (2015). Annual research review: A meta-analysis of the worldwide prevalence of mental disorders in children and adolescents. Journal of Child Psychology and Psychiatry and Allied Disciplines, 56(3), 345-365. https://doi.org/10.1111/jcpp.12381.

Prinstein, M. J., Boergers, J., \& Vernberg, E. M. (2001). Overt and relational aggression in adolescents: Social-psychological adjustment of aggressors and victims. Journal of Clinical Child \& Adolescent Psychology, 30(4), 479-491. https://doi.org/10.1207/ S15374424JCCP3004_05.

Ranta, K., Kaltiala-Heino, R., Frojd, S., \& Marttunen, M. (2013). Peer victimization and social phobia: A follow-up study among adolescents. Social Psychiatry and Psychiatric Epidemiology, 48(4), 533-544. https://doi.org/10.1007/s00127-012-0583-9.

Ranta, K., Kaltiala-Heino, R., Rantanen, P., \& Marttunen, M. (2009). Social phobia in Finnish general adolescent population: Prevalence, comorbidity, individual and family correlates, and service use. Depression and Anxiety, 26(6), 528-536. https://doi. org/10.1002/da.20422.

Richman, J. M., \& Bowen, G. L. (1997). School failure: An ecologicalinteractional-developmental perspective. In M. W. Fraser (Ed.), Risk and resilience in childhood: An ecological perspective (pp. 95-116). Washington, DC: NASW Press.

Rose, A. J., \& Rudolph, K. D. (2006). A review of sex differences in peer relationship processes: Potential trade-offs for the emotional and behavioural development of girls and boys. Psychological Bulletin, 132(1), 98-131. https://doi. org/10.1037/0033-2909.132.1.98.

Scaini, S., Belotti, R., \& Ogliari, A. (2014). Genetic and environmental contributions to social anxiety across different ages: A metaanalytic approach to twin data. Journal of Anxiety Disorders, 28(7), 650-656. https://doi.org/10.1016/j.janxdis.2014.07.002.

Schwartz, C. E., Snidman, N., \& Kagan, J. (1999). Adolescent social anxiety as an outcome of inhibited temperament in childhood. Journal of the American Academy of Child and Adolescent Psychiatry, 38(8), 1008-1015. https://doi.org/10.1097/00004583199908000-00017.

Siegel, R. S., la Greca, A. M., \& Harrison, H. M. (2009). Peer victimization and social anxiety in adolescents: Prospective and reciprocal relationships. Journal of Youth and Adolescence, 38(8), 1096-1109. https://doi.org/10.1007/s10964-009-9392-1.

Spence, S. H., \& Rapee, R. M. (2016). The etiology of social anxiety disorder: An evidence-based model. Behaviour Research and Therapy, 86, 50-67. https://doi.org/10.1016/j.brat.2016.06.007.

Starr, L. R., \& Davila, J. (2008). Differentiating interpersonal correlates of depressive symptoms and social anxiety in adolescence: Implications for models of comorbidity. Journal of Clinical Child \& Adolescent Psychology, 37(2), 337-349. https://doi. org/10.1080/15374410801955854.

Stein, M. B., Chartier, M. J., Hazen, A. L., Kozak, M. V., Tancer, M. E., Lander, S., ... Walker, J. R. (1998). A direct-interview family study of generalized Social Phobia. The American Journal of Psychiatry, 155(1), 90-97. https://doi.org/10.1176/ajp.155.1.90. 
Stein, M. B., Fuetsch, M., Müller, N., Höfler, M., Lieb, R., \& Wittchen, H.-U. (2001). Social Anxiety Disorder and the risk of depression. Archives of General Psychiatry, 58(3), 251. https://doi. org/10.1001/archpsyc.58.3.251.

Stein, M. B., \& Kean, Y. M. (2000). Disability and quality of life in social phobia: Epidemiologic findings. The American Journal of Psychiatry, 157(10), 1606-1613. https://doi.org/10.1176/appi. ajp.157.10.1606.

Storch, E. A., Brassard, M. R., \& Masia-Warner, C. L. (2003a). The relationship of peer victimization to social anxiety and loneliness in adolescence. Child Study Journal, 33(1), 1-18.

Storch, E. A., \& Masia-Warner, C. (2004). The relationship of peer victimization to social anxiety and loneliness in adolescent females. Journal of Adolescence, 27(3), 351-362. https://doi. org/10.1016/j.adolescence.2004.03.003.

Storch, E. A., Masia-Warner, C., Crisp, H., \& Klein, R. G. (2005). Peer victimization and social anxiety in adolescence: A prospective study. Aggressive Behavior, 31(5), 437-452. https://doi. org/10.1002/ab.20093.

Storch, E. A., Phil, M., Nock, M. K., Masia-Warner, C., \& Barlas, M. E. (2003b). Peer victimization and social-psychological adjustment in Hispanic and African-American children. Journal of Child and Family Studies, 12(4), 439-452. https://doi.org/10.1023/A:10260 16124091.

Tillfors, M. (2004). Why do some individuals develop social phobia? A review with emphasis on the neurobiological influences. Nordic Journal of Psychiatry, 58(4), 267-276. https://doi. org/10.1080/08039480410005774.

Tillfors, M., Persson, S., Willen, M., \& Burk, W. J. (2012). Prospective links between social anxiety and adolescent peer relations. Journal of Adolescence, 35(5), 1255-1263. https://doi.org/10.1016/j. adolescence.2012.04.008.

Van Ameringen, M., Mancini, C., \& Farvolden, P. (2003). The impact of anxiety disorders on educational achievement (English). Journal of Anxiety Disorders, 17(5), 561-571.

van der Ploeg, R., Steglich, C., Salmivalli, C., \& Veenstra, R. (2015). The intensity of victimization: Associations with children's psychosocial well-being and social standing in the classroom. PLoS ONE, 10(10), 1-15. https://doi.org/10.1371/journal.pone.01414 90.

Van Oort, F. V. A., Greaves-Lord, K., Ormel, J., Verhulst, F. C., \& Huizink, A. C. (2011). Risk indicators of anxiety throughout adolescence: The trails study. Depression and Anxiety, 28(6), 485-494. https://doi.org/10.1002/da.20818.

Van Zalk, N., \& Van Zalk, M. (2015). The importance of perceived care and connectedness with friends and parents for adolescent social anxiety. Journal of Personality, 83(3), 346-360. https:// doi.org/10.1111/jopy.12108.

Vernberg, E. M. (1990). Psychological adjustment and experiences with peers during early adolescence: Reciprocal, incidental, or unidirectional relationships? Journal of Abnormal Child Psychology, 18(2), 187-198. https://doi.org/10.1007/BF00910730.

Vernberg, E. M., Abwender, D. A., Ewell, K. K., \& Beery, S. H. (1992). Social anxiety and peer relationships in early adolescence: A prospective analysis. Journal of Clinical Child Psychology, 21(2), 189-196. https://doi.org/10.1207/s15374424jccp2102_11.

Walters, K. S., \& Inderbitzen, H. M. (1998). Social anxiety and peer relations among adolescents: Testing a psychobiological model. Journal of Anxiety Disorders, 12(3), 183-198. https://doi. org/10.1016/S0887-6185(98)00008-5.

Wittchen, H. U., Fuetsch, M., Sonntag, H., Muller, N., \& Liebowitz, M. (2000). Disability and quality of life in pure and comorbid social phobia. Findings from a controlled study. European Psychiatry, 15(1), 46-58. https://doi.org/10.1016/s0924-9338(00)00211-x.

Woodward, L. J., \& Fergusson, D. M. (2001). Life course outcomes of young people with anxiety disorders in adolescence. Journal of the American Academy of Child \& Adolescent Psychiatry, 40(9), 1086-1093. https://doi.org/10.1097/00004583-20010 9000-00018.

Yen, C.-F., Huang, M.-F., Kim, Y. S., Wang, P.-W., Tang, T.-C., Yeh, Y.-C., ... Yang, P. (2013). Association between types of involvement in school bullying and different dimensions of anxiety symptoms and the moderating effects of age and gender in Taiwanese adolescents. Child Abuse and Neglect, 37(4), 263-272. https://doi.org/10.1016/j.chiabu.2013.01.004.

Publisher's Note Springer Nature remains neutral with regard to jurisdictional claims in published maps and institutional affiliations. 